\title{
Proposição de um índice de desempenho ambiental da manutenção rodoviária
}

\section{Proposition of an environmental performance index of road maintenance}

\author{
Roque Rodrigo Rodrigues ${ }^{1}$, Heliana Barbosa Fontenele ${ }^{2}$ \\ 1Universidade Estadual de Londrina, Paraná - Brasil, roque_rodrygues@hotmail.com \\ 2Universidade Estadual de Londrina, Paraná - Brasil, heliana@uel.br
}

\section{Recebido:}

20 de junho de 2018

Aceito para publicação:

30 de novembro de 2019

Publicado:

31 de agosto de 2020

Editor de área:

Kamilla Vasconcelos

\section{Palavras-chaves:}

Gestão ambiental.

MACBETH.

Impactos ambientais.

Conservação rodoviária.

Keywords:

Environmental management.

MACBETH.

Environmental impacts.

Road maintenance.

DOI:10.14295/transportes.v28i3.1786

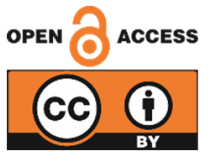

\begin{abstract}
RESUMO
$\mathrm{O}$ desenvolvimento e o atendimento às diretrizes propostas nos programas ambientais são fundamentais para minimizar os impactos gerados pelas obras de manutenção rodoviária. Portanto, o objetivo da pesquisa é desenvolver um Índice de Desempenho Ambiental da Manutenção Rodoviária. $\mathrm{O}$ índice é composto por 59 indicadores ambientais criados com base na metodologia multicritério construtivista. Os indicadores foram divididos hierarquicamente em grupos e subgrupos e julgados, segundo o método de mensuração de atratividade com uso de técnicas de avaliação baseada em categorias. Constatou-se que alguns critérios são específicos para o local e a realidade dos especialistas entrevistados, entretanto pode ser feita a remoção e redistribuição dos pesos sem alterar o resultado final. Conclui-se que o índice pode ser uma ferramenta versátil para auxiliar o gestor na definição de metas e reconhecimento de condições que necessitam ser aprimoradas.
\end{abstract}

\begin{abstract}
The development and compliance with the proposed guidelines in the environmental programs are fundamental to minimize the impacts generated by road maintenance works. Therefore, the objective of the research is to develop a Road Maintenance Environmental Performance Index. The index consists of 59 environmental indicators based on the constructivist multicriteria methodology. The indicators were divided into hierarchical groups and subgroups and judged according to the attractiveness measurement method by a category-based assessment technique. It was found that some criteria are specific to the location and reality of the interviewed experts; however the weights removal and redistribution can be done without changing the final result. It can be concluded that the index can be a versatile tool to assist the manager in setting goals and recognizing conditions that need improvement.
\end{abstract}

\section{INTRODUÇÃO}

A infraestrutura de transporte desempenha um papel fundamental no desenvolvimento econômico de um país. A área rodoviária, da qual a economia brasileira é bastante dependente para suprir a demanda comercial e industrial interna ou o transporte de insumos e mercadorias para exportações, apresenta atividades que geram consideráveis impactos negativos sobre o meio ambiente.

É preciso que esses impactos ambientais sejam previstos e controlados, não somente durante a construção e operação, mas também ao logo das atividades de manutenção. Em relação a essas últimas, observa-se a dificuldade na supervisão ambiental devido às diversas variáveis ambientais geradas durante a etapa. Costa e Granemann (2015) afirmam que é comum a 
utilização de indicadores e índices para mensurar e avaliar os vários critérios do desempenho ambiental deste tipo de serviço.

Os indicadores e índices, de acordo com Díaz e Silva (2015), traduzem e sintetizam comportamentos ou fenômenos naturais pelo estabelecimento de parâmetros qualitativos ou quantitativos e permitem a observação da evolução, ou o estabelecimento de uma relação, entre as variáveis ambientais consideradas. Dessa forma, possibilita avaliar o desempenho e sua evolução ao longo do tempo quando comparado a períodos anteriores, a situações semelhantes e no estabelecimento de metas. Contudo, Gallardo e Sánchez (2004) reforçam que estas ferramentas devem possuir mecanismos simples e estáveis para avaliação dos critérios e para o acompanhamento de sua evolução.

Caminhando nessa direção, a interação de variados indicadores poderá ocorrer por meio de uma escala em comum, permitindo a agregação destes em um índice global. Esse processo poderá ser facilitado por meio da utilização de métodos de apoio multicritério à decisão para organizar os diferentes indicadores na composição de um índice global. Dentre eles destaca-se o método MACBETH (do inglês Measuring Attractiveness by a Category Based Evaluation Technique). 0 método permite traduzir o julgamento semântico de atratividade entre os indicadores $\mathrm{e}$ entre as áreas de interesse para uma função de valor que representará, a partir de uma pontuação, o impacto de cada nível de desempenho. Além disso, também fornece o peso de cada componente na estrutura final do índice.

A partir do exposto, o objetivo desta pesquisa foi desenvolver um índice para avaliação do desempenho ambiental da manutenção rodoviária, tendo como base a pesquisa de Jesus (2015) que determinou uma série de indicadores ambientais, relativos aos serviços de manutenção rodoviária, a partir do uso da Metodologia de Apoio à Decisão Construtivista (MCDA-C, do inglês Multicriteria Decision Analysis Constructivist).

Assim, o Índice de Desempenho Ambiental da Manutenção Rodoviária (IDA-MR) foi desenvolvido. O IDA-MR é constituído por 59 indicadores, tanto quantitativos quanto qualitativos, divididos em grupos e subgrupos. A operacionalização ocorreu por meio do método MACBETH, que a partir dos julgamentos de diferença de atratividade permitiu definir uma pontuação a cada nível de desempenho considerado, bem como pesos de ponderação aos indicadores e aos seus respectivos grupos.

A importância desta pesquisa remete, em primeiro momento, a uma inovação na área devido à escassez e insuficiência de instrumentos de monitoramento do desempenho ambiental rodoviário, processo atualmente limitado ao licenciamento com elaboração de Estudos de Impactos Ambientais e Relatórios de Impactos Ambientais. 0 desenvolvimento desses dispositivos é fundamental para um acompanhamento detalhado e contínuo das atividades. Assim, condições ambientais frágeis e capazes de recuperação poderão ser identificadas e as medidas mitigadoras planejadas e aplicadas contribuindo para a redução dos impactos ambientais negativos.

\section{GESTÃO AMBIENTAL RODOVIÁRIA}

Na área da gestão ambiental rodoviária a análise do nível de impacto ambiental dos serviços realizados apresenta complexidade devido à presença de diversos fatores a serem monitorados. Dessa forma, corrobora-se a afirmação de Gomes e Malheiros (2012) sobre a importância da utilização de indicadores apropriados ao compor instrumentos para a avaliação ambiental integrada. Para os autores, os critérios para a análise dos pontos fortes e fracos dos indicadores e 
procedimentos para sua aplicação deverão, por exemplo: possuir valores de referência, ter sensibilidade às mudanças no ambiente, ser de fácil compreensão, ter validade científica, estar disponível e ser fácil de obter.

Levando isso em consideração, vários trabalhos ao longo do mundo têm proposto indicadores e índices na área ambiental. Como exemplos de algumas pesquisas relativas ao tema, e focadas na questão rodoviária, destacam-se neste artigo a de Ratton et al. (2013), a de Costa e Sánchez (2010), e a de Jesus (2015).

No trabalho de Ratton et al. (2013) foi salientado a aplicação de fichas de monitoramento ambiental durante a supervisão e execução dos programas ambientais relativos às obras de recuperação e implantação de acostamentos da BR-262 (Programa Ambiental da Construção, Programa de Recuperação de Áreas Degradadas, Programa de Prevenção de Processos Erosivos, Programa de Gerenciamento de Resíduos Sólidos e Efluentes Líquidos e Programa de Prevenção de Acidentes). As fichas contemplavam 51 tópicos de avaliação, como por exemplo: "Há condições de segurança no armazenamento e manuseio de combustíveis e produtos inflamáveis?” e "Foram identificados pontos críticos com maior probabilidade de acidentes com cargas perigosas? Se sim, há medidas de prevenção?". o check list com o registro das ocorrências foi realizado semanalmente e com base em índices de satisfação e atendimento à regularidade ambiental de cada item. Os níveis de atribuição variavam entre 1 a 4 , correspondendo respectivamente a: "Não atendimento" (quando o aspecto ambiental foi atendido em até 25\%) e "Plenamente atendido" (quando o aspecto ambiental foi atendido de 75\% a 100\%). Na análise entre os resultados das inspeções foi observado que houve melhorias significativas no desempenho ambiental, evidenciando, portanto, que a utilização de indicadores e o acompanhamento contínuo dos programas têm um reflexo positivo na minimização e controle dos impactos ambientais.

Já para avaliar o desempenho ambiental em obras de recuperação de rodovias, Costa e Sánchez (2010) desenvolveram o Índice de Não Conformidade Ambiental Crítico (INCACR). Segundo a escala do índice, obras cuja pontuação está abaixo de 2 possuem desempenho ambiental altamente satisfatório e acima de 12,1 um desempenho altamente insatisfatório. São considerados na sua composição os critérios: Gravidade (severidade, potencial de causar degradação ambiental em áreas adjacentes, facilidade de implementação de ação corretiva e localização); implementação de ação corretiva (em atendimento, atendida, pendente e não atendida) e reincidência (número de eventos reincidentes). A atribuição dos pesos para cada critério foi baseada na opinião de profissionais de alto conhecimento da área. Os autores concluem que o INCACR define o valor máximo a partir do qual o desempenho é considerado indesejado e, além disso, é um instrumento representativo e útil na avaliação de desempenho ambiental de empreendimentos rodoviários, desde que os mesmos critérios adotados na pesquisa sejam utilizados na avaliação.

Ainda com foco nos serviços relacionados à manutenção de estradas pavimentadas, Jesus (2015) desenvolveu indicadores a partir da aplicação da MCDA-C. 0 método utilizado emprega, além dos critérios objetivos e quantitativos no processo de tomada de decisão, fatores subjetivos. Ao longo do processo a interação e a participação dos decisores são fundamentais para gerar os modelos de análise. Assim, estes elementos foram estabelecidos de acordo com os pontos de vista obtidos em workshops realizados com alunos de mestrado e com profissionais do órgão rodoviário de 5 regionais do estado do Paraná. Ao todo foram obtidos 185 conceitos, os quais foram filtrados em 82 critérios pertencentes às seguintes áreas: água; gestão; equipe; jurídico; materiais; meio biótico; fauna; vegetação; segurança viária e socioambiental. 
Além disso, também foi gerada a descrição dos critérios de avaliação e a determinação dos seus respectivos indicadores. Os indicadores gerados na sua pesquisa foram analisados e ajustados, conforme será abordado posteriormente.

\section{MÉTODO MACBETH}

MACBETH é um método baseado na análise multicritério de decisão construtivista idealizado por Carlos Antonio Bana e Costa e Jean-Claude Vansick em 1994. Nele a tomada de decisão é feita por meio da medição da atratividade com uso de técnicas de avaliação baseada em categorias. A partir dos julgamentos dos decisores, e respeitando as diferenças de atratividade entre duas alternativas, são construídas escalas de intervalos numéricos (Perdigão et al., 2012).

Assim pode-se dizer que este método traduz numericamente os julgamentos dos decisores quanto à atratividade global das ações, incorporando a representação numérica da informação aos critérios ou pontos de vistas analisados. A preferência do decisor entre os pares de alternativas é quantificada por uma escala de atratividade de 6 categorias semânticas: muito fraca; fraca; moderada; forte; muito forte; extrema (Bana e Costa et al., 2013).

Para facilitar a operacionalização do processo, os idealizadores desenvolveram o software M-MACBETH, homônimo do método. De acordo com Bana e Costa et al. (2013), o software contêm modelos de programação linear para realizar a transformação da informação ordinal para cardinal. Isso é facilitado por meio do questionamento, não numérico, de comparação qualitativa pareada das opções. Ao final, os vários critérios julgados são sintetizados em um índice global por meio de somas ponderadas. Bana e Costa et al. (2004) e Bana e Costa et al. (2013) comentam que uma verificação de consistência ocorre automaticamente conforme os julgamentos são inseridos no software. Quando uma inconsistência é encontrada, a origem do problema é identificada pelo M-MACBETH e, são oferecidas sugestões de alteração para eliminá-la. Assim sendo, este software apresentou-se viável ao desenvolvimento do IDA-MR.

\section{MÉTODO}

0 método de pesquisa está dividido em 2 fases: estruturação e avaliação. A primeira fase contém a definição da base de dados, as áreas de interesse, os ajustes e a definição dos níveis de referência dos critérios de avaliação e grupos. A segunda fase aborda a definição das escalas no MACBETH, o julgamento semântico de atratividade intercritério, entre critérios e entre grupos, finalizando com o modelo adotado para agregação dos critérios e grupos no IDA-MR.

\subsection{Fase de estruturação}

Esta fase iniciou com a revisão e análise simultânea dos critérios de avaliação e os correspondentes indicadores obtidos por Jesus (2015). Neste trabalho optou-se por se referir a eles como "critérios e indicadores originais". Tais critérios e indicadores foram baseados na opinião de profissionais de diversas áreas relacionadas com a temática ambiental e manutenção de rodovias. Após a análise verificou-se a necessidade de ajustes e atribuição das suas unidades de mensuração.

Assim, os critérios e indicadores originais foram dispostos em planilhas de um software de processamento de dados e separados por cada área de interesse (grupos e subgrupos). 0 procedimento ocorreu a partir de discussão entre os autores do artigo (decisores) sobre os dados originais. As decisões foram apoiadas tanto na revisão bibliográfica quanto no 
conhecimento técnico. A atuação de apenas dois decisores na elaboração do IDA-MR foi devida ao alto volume de dados a serem analisados, a complexidade do processo de julgamento e a disponibilidade de participação na pesquisa.

Com o objetivo de verificar sombreamentos entre os indicadores, detectando aqueles com definições e propósitos similares reunidos em diferentes áreas de interesse, fez-se a impressão individual dos critérios de cada área de interesse e a comparação entre si para averiguar a necessidade de readequações (mesclagem, reagrupamento ou exclusão). 0 ajuste dos critérios e indicadores foi finalizado com a depuração da descrição de cada um, com base na revisão bibliográfica de manuais e relatórios técnicos, normas, procedimentos e artigos relacionados à gestão ambiental rodoviária.

Na sequência foram criados os níveis de avaliação de cada indicador com base em pesquisa bibliográfica e no conhecimento técnico dos decisores. No geral foram adotados cinco níveis, dentre eles destacam-se os níveis de referência para caracterizar o limite aceitável mínimo (neutro) e o satisfatório (bom).

Além disso, a hierarquização dos indicadores e grupos foi feita para identificar a atratividade decrescente entre os indicadores de cada grupo e também entre os grupos. Assim, os decisores classificaram os níveis de desempenho de determinado critério por ordem decrescente de atratividade tendo como base os níveis de referência predefinidos, ou seja, estabeleceram qual nível de desempenho era mais atrativo do que o outro.

Os níveis foram posteriormente inseridos no software M-MACBETH na ordem determinada anteriormente. 0 programa relaciona cada nível de determinado critério em matrizes para a realização da comparação pareada.

\subsection{Fase de avaliação}

Nesta fase são abordados os processos realizados para a determinação das escalas de valor cardinais, a forma e perguntas utilizadas no julgamento semântico e a escala MACBETH obtida, bem como o processo para obter a informação entre critérios e entre grupos e sua correspondente escala de atratividade global, finalizando com o modelo de agregação empregado no IDAMR. Este tipo de modelo permite agregar as pontuações numa combinação linear ponderada, proporcionando uma compensação entre os critérios.

\subsubsection{Construção da função de valor MACBETH}

Tendo em vista que o IDA-MR possui grupos e subgrupos, realizou-se o julgamento de atratividade dos critérios de cada grupo individualmente, pois o software realiza a análise de apenas um grupo de indicadores por vez, não sendo possível o julgamento de indicadores em subgrupos paralelos. Inicialmente foram julgados os indicadores dos subgrupos, em seguida os dos grupos e por último o julgamento entre os grupos.

O julgamento de atratividade entre os níveis de cada indicador, se baseou no seguinte questionamento: "Dado que o nível A é mais atrativo que o nível $\mathrm{B}$, que diferença de atratividade você sente entre o nível A e B: muito fraca, fraca, moderada, forte, muito forte ou extrema? Ou seja, qual o impacto de passar o nível B para o nível A?". Após, os decisores verificavam a escala cardinal sugerida pelo M-MACBETH para cada nível daquele indicador. Os ajustes necessários eram realizados respeitando os limites fornecidos pelo software de forma a não alterar a matriz de julgamento. 


\subsubsection{Pesos}

Os pesos foram determinados com base na importância relativa dos critérios. 0 procedimento para determinação dos pesos foi dividido em duas etapas principais: ordenação prévia dos critérios e geração de uma escala.

Inicialmente foram elaboradas matrizes com os critérios de determinado grupo e realizado um questionamento sobre a preferência entre os critérios: "Considere-se uma alternativa fictícia com um nível neutro em todos os critérios. Sendo possível melhorar o impacto de neutro para bom num só critério, mantendo todos os demais no nível neutro, seria mais atrativo passar para o nível bom o critério A ou o critério B?".

Para a resposta afirmativa foi atribuído o valor de 1, para resposta negativa o valor de 0 . Ao final, a soma das linhas da matriz determinou a ordem decrescente de atratividade global dos critérios. 0 mesmo julgamento foi feito entre os grupos, com objetivo de determinar a hierarquização entre eles. Esta ordenação foi utilizada para configurar a matriz de julgamento de atratividade.

A segunda etapa iniciou com a construção da matriz de julgamento de atratividade, semelhante àquelas construídas para determinação da função de valor MACBETH para os critérios. 0 critério considerado mais atrativo ficou localizado em linha mais acima que os demais, e em coluna, mais à esquerda. Assim, o preenchimento da matriz triangular superior dos julgamentos de atratividade foi feito com base na questão: “Uma vez que passar do nível neutro para o nível bom no Critério-X1 foi considerado mais atrativo do que no Critério-X2, mantendo todos os demais constantes, esta diferença de atratividade é muito fraca, fraca, moderada...?".

Após o julgamento os decisores verificaram os pesos sugeridos pelo M-MACBETH para cada indicador daquele grupo/subgrupo. Os ajustes necessários eram realizados respeitando os limites fornecidos pelo software de forma a não alterar a matriz de julgamento. 0 mesmo procedimento foi realizado para o julgamento entre os grupos para obtenção dos pesos na composição do IDA-MR.

\subsubsection{Definição do IDA-MR}

A aplicação do modelo aditivo hierárquico de agregação das avaliações dos trechos analisados pelos vários grupos e subgrupos identificados, considerando os coeficientes de ponderação, traduziu-se na determinação do Índice de Desempenho Ambiental da Manutenção Rodoviária Global. Matematicamente, para cada trecho, o IDA-MR é expresso pela sua pontuação global dada por:

$$
I D A-M R_{G(a)}=\sum_{i}^{n} p_{i} \cdot v_{i}(a)
$$

onde: IDA-MR $\mathrm{G}_{\mathrm{G}(\mathrm{a})}$ Índice de Desempenho Ambiental da Manutenção Rodoviária Global da Obra "a";;

pi: $\quad$ Peso correspondente ao critério i (PVFi), i=1, 2,.., n;

$\mathrm{V}_{\mathrm{i}}$ : $\quad$ Valor Parcial de uma obra "a" no critério i, i=1, 2,..., n.

0 modelo apresentado para o IDA-MR é utilizado também para a agregação dos indicadores nos seus respectivos grupos e subgrupos.

\section{RESULTADOS}

Este item aborda os indicadores ajustados, abrangendo o critério de avaliação, unidade de mensuração, os níveis de desempenho, ordenação segundo a atratividade, a função de valor 
MACBETH para cada indicador, seus pesos e também o equacionamento do desempenho de cada grupo e do IDA-MR. É importante destacar que para a utilização do índice proposto nesta pesquisa, recomenda-se que sejam adotados trechos de 1,0 quilômetro, pois assim não há o cansaço dos avaliadores e, como uma rodovia possui grandes extensões, com trechos pequenos tem-se um acompanhamento individualizado de cada um, permitindo ações de maneira rápida para melhorar o desempenho ambiental.

\subsection{Fase de estruturação}

Durante a fase de estruturação foram identificados os aspectos importantes da gestão ambiental rodoviária indicados na pesquisa de Jesus (2015), bem como reorganizados nos seguintes grupos/subgrupos: Grupo Água; Grupo Gestão e subgrupo Equipe; Grupo Jurídico; Grupo Materiais; Grupo Meio Biótico e subgrupos Fauna e Vegetação; grupo Segurança ambiental e Grupo Socioambiental.

Durante a análise dos dados originais observou-se que alguns indicadores possuíam uma alta complexidade para sua avaliação e mensuração, ou pareciam estar fora de sua área de interesse, inviabilizando sua adoção como indicador. Como exemplo pode ser citado a exclusão do critério original "Conformidade de solos adjacentes", cuja proposta de mensuração se baseava na verificação da topografia dos solos conforme projetos. A decisão foi tomada mediante a complexidade para obter dados de acompanhamento e a dificuldade de definir níveis de desempenho para serem os parâmetros de avaliação. Assim, do total de 84 critérios originais foram adotados 59 critérios de avaliação e seus respectivos indicadores.

No geral, os indicadores estão relacionados à existência de programas, procedimentos e campanhas que visam a redução e/ou eliminação dos impactos ambientais, bem como há indicadores voltados para a mensuração dos passivos ambientais causados pela manutenção ou pela falta dela.

Para sintetizar os resultados deste item foram utilizadas todas as informações a respeito dos critérios de avaliação, indicadores, descrição e níveis de desempenho de cada grupo que estão reunidas e disponibilizadas nas Tabelas 1 a 5. Os níveis de referências bom e neutro estão identificados nas cores verde e azul, respectivamente. Cabe frisar que os níveis de desempenho se encontram hierarquizados segundo a atratividade decrescente.

Para o grupo Água (A) os dados compilados da fase de estruturação são apresentados na Tabela 1. De modo geral, os critérios deste grupo têm como objetivo verificar a existência de programas de monitoramento, manutenção e controle do sistema de drenagem até a presença de pontos de assoreamento e erosão.

Observa-se que alguns critérios do grupo Água (A) apresentam certa similaridade ou sombreamento. É o caso dos critérios A1 e A6, pois caso o critério A6 seja atendido consequentemente não haverá problemas com o A1. Os critérios A2 e A4 também possuem sombreamento, pois o assoreamento é uma consequência da erosão. Entretanto, os decisores avaliaram que o critério A2 apresenta como ponto positivo a conservação dos corpos hídricos, enquanto que o critério A4 tem como objetivo controlar as erosões com os sistemas de drenagem. 0 mesmo pode ser visto quanto aos critérios A6 e A7. 0 critério A6 visa garantir o bom funcionamento do sistema de drenagem, evitando o descontrole e emergências nos sistemas. Enquanto que o critério A7 é justificado por adequar os sistemas às condições atuais. Desta forma, foi decidido mantê-los tendo em vista que os decisores originalmente elegeram tais critérios como 
fundamentais para a avaliação do desempenho. Portanto, eles devem ser adotados e analisados separadamente, obedecendo às propriedades de inteligibilidade, operacionalidade e consensualidade.

Tabela 1 - Critérios de avaliação do grupo Água (A)

\begin{tabular}{|c|c|c|c|c|c|}
\hline Critério & & $\begin{array}{l}\text { A1 - Água superficial na plata- } \\
\text { forma }\end{array}$ & A2 - Assoreamento & $\begin{array}{c}\text { A3 - Plano de } \\
\text { contingência para } \\
\text { desastres com chuva }\end{array}$ & A4 - Erosão \\
\hline \multicolumn{2}{|l|}{ Indicador } & $\begin{array}{l}\text { Porcentagem da área do } \\
\text { pavimento com escoamento } \\
\text { deficiente (poça d'água) }\end{array}$ & $\begin{array}{c}\text { Existência de programa } \\
\text { de monitoramento de } \\
\text { pontos de } \\
\text { assoreamento }\end{array}$ & $\begin{array}{l}\text { Existência de plano de } \\
\text { contingência para } \\
\text { desastres com chuva }\end{array}$ & $\begin{array}{l}\text { Porcentagem do trecho } \\
\text { com erosão }\end{array}$ \\
\hline \multicolumn{2}{|l|}{ Unidade } & $\%$ & - & - & $\%$ \\
\hline \multicolumn{2}{|l|}{ Descrição } & $\begin{array}{l}\text { Relacionado à manutenção do } \\
\text { pavimento em função da ação } \\
\text { de chuvas e projeto de drena- } \\
\text { gem, além da } \\
\text { segurança dos usuários } \\
\text { devido à aquaplanagem dos } \\
\text { veículos }\end{array}$ & $\begin{array}{l}\text { Programa ou plano de } \\
\text { monitoramento dos } \\
\text { pontos de } \\
\text { assoreamento dos } \\
\text { corpos hídricos } \\
\text { presentes no trecho } \\
\text { analisado }\end{array}$ & $\begin{array}{l}\text { Relacionado à existência de } \\
\text { plano de contingência de } \\
\text { desastres com chuva }\end{array}$ & $\begin{array}{l}\text { Porcentagem do trecho } \\
\text { analisado com erosão, } \\
\text { levando em consideração } \\
\text { a área da plataforma e } \\
\text { faixa de domínio }\end{array}$ \\
\hline \multirow{5}{*}{$\begin{array}{l}\text { Níveis de } \\
\text { desempenho }\end{array}$} & 1 & 0 & Existe & Existe & 0 \\
\hline & 2 & 10 & $\begin{array}{c}\text { Existe, mas necessita de } \\
\text { melhoria }\end{array}$ & $\begin{array}{c}\text { Existe, mas necessita de me- } \\
\text { Ihoria }\end{array}$ & 10 \\
\hline & 3 & 15 & $\begin{array}{c}\text { Não existe, mas está em } \\
\text { elaboração }\end{array}$ & $\begin{array}{l}\text { Não existe, mas está em ela- } \\
\text { boração }\end{array}$ & 15 \\
\hline & 4 & 25 & Não existe & Não existe & 25 \\
\hline & 5 & 50 & & & 50 \\
\hline Critério & & $\begin{array}{c}\text { A5 - Impermeabilidade do } \\
\text { solo }\end{array}$ & $\begin{array}{c}\text { A6 - Manutenção dos } \\
\text { sistemas de } \\
\text { drenagem }\end{array}$ & A7 - Medidas preventivas & $\begin{array}{c}\text { A8 - Programa de } \\
\text { monitoramento da } \\
\text { drenagem }\end{array}$ \\
\hline \multicolumn{2}{|l|}{ Indicador } & $\begin{array}{c}\text { Porcentagem da área } \\
\text { impermeável da faixa de } \\
\text { domínio }\end{array}$ & $\begin{array}{l}\text { Porcentagem de } \\
\text { atendimento das } \\
\text { ordens de serviço }\end{array}$ & $\begin{array}{c}\text { Frequência de } \\
\text { monitoramento dos } \\
\text { sistemas de drenagem }\end{array}$ & $\begin{array}{c}\text { Existência de programa de } \\
\text { monitoramento dos siste- } \\
\text { mas de drenagem }\end{array}$ \\
\hline \multicolumn{2}{|l|}{ Unidade } & $\%$ & $\%$ & $\begin{array}{c}\text { N. de visitas/mês por tre- } \\
\text { cho da rodovia }\end{array}$ & - \\
\hline \multicolumn{2}{|l|}{ Descrição } & $\begin{array}{c}\text { Aponta a situação da } \\
\text { impermeabilidade do solo da } \\
\text { faixa de domínio do trecho } \\
\text { analisado }\end{array}$ & $\begin{array}{c}\text { Verificação da } \\
\text { quantidade de } \\
\text { manutenções atendidas } \\
\text { e que tiveram a ordem } \\
\text { de serviço cumprida }\end{array}$ & $\begin{array}{c}\text { Verificar a adoção de } \\
\text { medidas preventivas que } \\
\text { auxiliem no bom } \\
\text { funcionamento do sistema } \\
\text { de drenagem }\end{array}$ & $\begin{array}{c}\text { O programa de } \\
\text { monitoramento visa } \\
\text { garantir o correto } \\
\text { funcionamento do } \\
\text { sistema de drenagem, a } \\
\text { qualidade da água e } \\
\text { adequação do sistema às } \\
\text { condições atuais }\end{array}$ \\
\hline \multirow{5}{*}{$\begin{array}{c}\text { Níveis de } \\
\text { desempenho }\end{array}$} & 1 & 0 & 100 & 4 & Existe \\
\hline & 2 & 5 & 85 & 3 & $\begin{array}{l}\text { Existe, mas necessita de } \\
\text { melhorias/ atualizações }\end{array}$ \\
\hline & 3 & 10 & 75 & 2 & $\begin{array}{c}\text { Não existe, mas está em } \\
\text { elaboração }\end{array}$ \\
\hline & 4 & 15 & 65 & 1 & Não existe \\
\hline & 5 & 20 & 55 & 0 & - \\
\hline
\end{tabular}

Os resultados para o grupo Gestão (B) estão dispostos na Tabela 2. Os indicadores deste grupo visam monitorar e mensurar atividades que tenham efeito sobre a gestão através de indicadores relacionados a planos de gerenciamento, contingência ambiental entre outros. Os decisores estabeleceram que os critérios B10 e B11 necessitam ter sua avaliação independente, novamente atendendo as propriedades de inteligibilidade, operacionalidade e consensualidade.

Na Tabela 3 são apresentados os dados compilados da fase de estruturação do subgrupo Equipe, grupo Jurídico (C) e Materiais (D). 
Tabela 2 - Critérios de avaliação do grupo Gestão (B)

\begin{tabular}{|c|c|c|c|c|c|c|c|}
\hline 은 & $\begin{array}{c}\text { B1 - } \\
\text { Compatibilização } \\
\text { de projetos com o } \\
\text { meio ambiente }\end{array}$ & $\begin{array}{l}\text { B2 - Controle } \\
\text { de carga }\end{array}$ & $\begin{array}{l}\text { B3 - Plano de } \\
\text { destinação de } \\
\text { resíduos sólidos }\end{array}$ & $\begin{array}{l}\text { B4 - Equipe } \\
\text { técnica }\end{array}$ & $\begin{array}{l}\text { B5 - Controle/ } \\
\text { Manutenção da } \\
\text { sinalização }\end{array}$ & $\begin{array}{c}\text { B6- } \\
\text { Monitoramento } \\
\text { de defeitos }\end{array}$ & $\begin{array}{c}\text { B7 - Patrulha ru- } \\
\text { ral }\end{array}$ \\
\hline $\begin{array}{l}\frac{1}{0} \\
\stackrel{0}{0} \\
\stackrel{.0}{0} \\
\underline{\underline{c}}\end{array}$ & $\begin{array}{l}\text { Porcentagem de } \\
\text { projetos executivos } \\
\text { que contêm } \\
\text { projetos de meio } \\
\text { ambiente }\end{array}$ & $\begin{array}{c}\text { Existência e } \\
\text { funcionalidade } \\
\text { de balanças para } \\
\text { o controle de } \\
\text { cargas }\end{array}$ & $\begin{array}{l}\text { Existência de plano } \\
\text { de destinação dos } \\
\text { resíduos da } \\
\text { manutenção viária }\end{array}$ & $\begin{array}{l}\text { Porcentagem em } \\
\text { relação a } \\
\text { pontuação máxima } \\
\text { obtida pela soma } \\
\text { aditiva dos critérios } \\
\text { do subgrupo } \\
\text { Equipe }\end{array}$ & $\begin{array}{c}\text { Existência de } \\
\text { medidas para } \\
\text { monitoramento e } \\
\text { otimização dos } \\
\text { sistemas de } \\
\text { manutenção de } \\
\text { sinalização nas } \\
\text { rodovias }\end{array}$ & $\begin{array}{l}\text { Existência de } \\
\text { programa de } \\
\text { monitoramento de } \\
\text { defeitos no } \\
\text { pavimento }\end{array}$ & $\begin{array}{l}\text { Existência de } \\
\text { programa da } \\
\text { patrulha rural para } \\
\text { manutenção e } \\
\text { readequação de } \\
\text { estradas não } \\
\text { pavimentadas }\end{array}$ \\
\hline $\begin{array}{l}\frac{0}{0} \\
\frac{\pi}{0} \\
\frac{0}{5}\end{array}$ & $\%$ & - & - & $\%$ & - & - & - \\
\hline 丞 & $\begin{array}{l}\text { Visa a previsão e } \\
\text { diminuição dos } \\
\text { impactos } \\
\text { ambientais nos } \\
\text { projetos executivos } \\
\text { por meio da } \\
\text { porcentagem de } \\
\text { projetos executivos } \\
\text { que possuem } \\
\text { projetos } \\
\text { relacionados ao } \\
\text { meio ambiente }\end{array}$ & $\begin{array}{c}\text { Verificar a } \\
\text { existência e } \\
\text { funcionalidade } \\
\text { de balanças para } \\
\text { o controle de } \\
\text { cargas na } \\
\text { rodovia do } \\
\text { trecho analisado }\end{array}$ & $\begin{array}{c}\text { Plano de } \\
\text { destinação dos } \\
\text { resíduos gerados } \\
\text { nas atividades de } \\
\text { manutenção, } \\
\text { abrangendo desde } \\
\text { o pavimento até a } \\
\text { faixa de domínio, } \\
\text { promovendo o } \\
\text { reaproveitamento, } \\
\text { reciclagem e } \\
\text { garantido a } \\
\text { destinação } \\
\text { adequada para } \\
\text { estes resíduos }\end{array}$ & $\begin{array}{l}\text { Mensurar a } \\
\text { qualidade da } \\
\text { equipe técnica, } \\
\text { avaliando desde } \\
\text { questões de } \\
\text { pesquisa, } \\
\text { treinamento e } \\
\text { multidisciplinari- } \\
\text { dade da equipe }\end{array}$ & $\begin{array}{l}\text { Relacionado à } \\
\text { segurança dos } \\
\text { usuários através da } \\
\text { manutenção da } \\
\text { sinalização }\end{array}$ & $\begin{array}{l}\text { Programa para } \\
\text { monitoramento de } \\
\text { defeitos do } \\
\text { pavimento } \\
\text { contendo inspeção } \\
\text { visual, inventário e } \\
\text { intervenção de } \\
\text { rotina }\end{array}$ & $\begin{array}{l}\text { Manutenção } \\
\text { preventiva e } \\
\text { readequação dos } \\
\text { acessos à rodovia } \\
\text { por estradas não } \\
\text { pavimentadas } \\
\text { utilizadas pelo } \\
\text { lindeiros }\end{array}$ \\
\hline \multirow{5}{*}{ 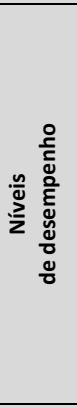 } & 100 & $\begin{array}{c}\text { Existe, } \\
\text { funcionamento } \\
\text { de } 24 \mathrm{~h}\end{array}$ & Existe & 100 & Existem & Existe & Existe \\
\hline & 75 & $\begin{array}{c}\text { Existe, } \\
\text { funcionamento } \\
\text { parcial }\end{array}$ & $\begin{array}{c}\text { Existe, mas } \\
\text { necessita de } \\
\text { melhorias/ } \\
\text { atualizações }\end{array}$ & 75 & $\begin{array}{l}\text { Existem, mas } \\
\text { necessitam de } \\
\text { atualizações }\end{array}$ & $\begin{array}{l}\text { Existe, mas } \\
\text { necessita de } \\
\text { melhorias/ } \\
\text { atualizações }\end{array}$ & $\begin{array}{c}\text { Existe, mas } \\
\text { necessita de } \\
\text { melhorias/ } \\
\text { atualizações }\end{array}$ \\
\hline & 50 & $\begin{array}{l}\text { Existe, mas não } \\
\text { está em } \\
\text { operação/Não } \\
\text { existe }\end{array}$ & $\begin{array}{l}\text { Não existe, mas } \\
\text { está em elaboração }\end{array}$ & 50 & $\begin{array}{c}\text { Não existem, mas } \\
\text { estão em } \\
\text { elaboração }\end{array}$ & $\begin{array}{l}\text { Não existe, mas } \\
\text { está em elaboração }\end{array}$ & $\begin{array}{l}\text { Não existe, mas } \\
\text { está em } \\
\text { elaboração/Não } \\
\text { existe }\end{array}$ \\
\hline & 25 & - & Não existe & 25 & Não existem & Não existe & - \\
\hline & 5 & - & & 0 & & - & - \\
\hline 赵 & $\begin{array}{l}\text { B8 - Plano de } \\
\text { contingência } \\
\text { ambiental }\end{array}$ & $\begin{array}{l}\text { B9-Plano de } \\
\text { contingência de } \\
\text { acidentes }\end{array}$ & $\begin{array}{l}\text { B10 - Plano de } \\
\text { gerenciamento }\end{array}$ & $\begin{array}{l}\text { B11 - Programas } \\
\text { ambientais }\end{array}$ & $\begin{array}{l}\text { B12 - Suporte } \\
\text { financeiro }\end{array}$ & B13 - Pesquisa & B14 - Treinamento \\
\hline 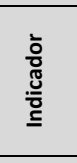 & $\begin{array}{l}\text { Existência de plano } \\
\text { de contingência } \\
\text { ambiental }\end{array}$ & $\begin{array}{l}\text { Existência de } \\
\text { plano de } \\
\text { contingência de } \\
\text { acidentes }\end{array}$ & $\begin{array}{l}\text { Existência de plano } \\
\text { de gerenciamento }\end{array}$ & $\begin{array}{l}\text { Desenvolvimento e } \\
\text { aplicação de } \\
\text { programas } \\
\text { ambientais }\end{array}$ & $\begin{array}{c}\text { Existência de } \\
\text { fundos monetários } \\
\text { para projetos } \\
\text { ambientais }\end{array}$ & $\begin{array}{c}\text { Tempo dedicado } \\
\text { para pesquisa } \\
\text { ambiental dentro } \\
\text { da jornada semanal } \\
\text { de trabalho } \\
\end{array}$ & $\begin{array}{l}\text { Frequência de } \\
\text { treinamentos para } \\
\text { a questão } \\
\text { ambiental }\end{array}$ \\
\hline $\begin{array}{l}\frac{0}{0} \\
\frac{\pi}{0} \\
\frac{0}{5}\end{array}$ & - & - & - & Atendimento & - & Horas/semana & $\begin{array}{c}\text { № de treinamentos } \\
\text { anuais }\end{array}$ \\
\hline 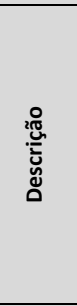 & $\begin{array}{c}\text { Plano de } \\
\text { contingência } \\
\text { ambiental } \\
\text { contendo as } \\
\text { providências para } \\
\text { enfrentar uma } \\
\text { situação de } \\
\text { emergência }\end{array}$ & $\begin{array}{c}\text { Plano de } \\
\text { contingência } \\
\text { para acidentes } \\
\text { no transporte de } \\
\text { produtos } \\
\text { perigosos, } \\
\text { contendo } \\
\text { procedimento de } \\
\text { ações de } \\
\text { emergência }\end{array}$ & $\begin{array}{c}\text { Plano de } \\
\text { gerenciamento } \\
\text { com foco na gestão } \\
\text { ambiental da } \\
\text { manutenção viária }\end{array}$ & $\begin{array}{c}\text { Programas } \\
\text { ambientais } \\
\text { desenvolvidos que } \\
\text { foram realmente } \\
\text { aplicados }\end{array}$ & $\begin{array}{l}\text { Orçamento anual } \\
\text { disponível ou } \\
\text { destinado para } \\
\text { projetos ambientais }\end{array}$ & $\begin{array}{l}\text { Tempo dedicado } \\
\text { pelos profissionais } \\
\text { para pesquisa } \\
\text { ambiental }\end{array}$ & $\begin{array}{c}\text { Frequência anual } \\
\text { de treinamentos } \\
\text { voltados para } \\
\text { questão ambiental, } \\
\text { incluindo educação } \\
\text { ambiental, cursos e } \\
\text { palestras } \\
\text { relacionadas à } \\
\text { gestão ambiental } \\
\text { dos serviços }\end{array}$ \\
\hline \multirow{5}{*}{ 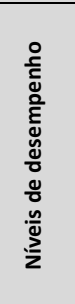 } & Existe & Existe & Existe & Sim & Sim & 20 & 4 \\
\hline & $\begin{array}{c}\text { Existe, mas } \\
\text { necessita de } \\
\text { melhorias/ } \\
\text { atualizações }\end{array}$ & $\begin{array}{c}\text { Existe, mas } \\
\text { necessita de } \\
\text { melhorias/ } \\
\text { atualizações }\end{array}$ & $\begin{array}{c}\text { Existe, mas } \\
\text { necessita de } \\
\text { melhorias/ } \\
\text { atualizações }\end{array}$ & Parcial & $\begin{array}{l}\text { Não, mas está em } \\
\text { desenvolvimento }\end{array}$ & 15 & 2 \\
\hline & $\begin{array}{c}\text { Não existe, } \\
\text { mas está em } \\
\text { elaboração }\end{array}$ & $\begin{array}{l}\text { Não existe, mas } \\
\text { está em } \\
\text { elaboração }\end{array}$ & $\begin{array}{l}\text { Não existe, mas } \\
\text { está em elaboração }\end{array}$ & Não & Não & 10 & 1 \\
\hline & Não existe & Não existe & Não existe & - & - & 5 & 0 \\
\hline & 5 & - & - & - & - & 0 & - \\
\hline
\end{tabular}


Tabela 3 - Critérios de avaliação do subgrupo Equipe, grupo Jurídico (C) e Materiais (D)

\begin{tabular}{|c|c|c|c|c|c|c|c|c|c|}
\hline Critério & & \multicolumn{4}{|c|}{ B42 - Equipe multidisciplinar } & \multicolumn{2}{|r|}{ B43 - Funções } & \multicolumn{2}{|r|}{ B44 - Transição } \\
\hline Indicador & & $\begin{array}{c}\text { Porcentagem de atendiment } \\
\text { aos planos ambientais }\end{array}$ & \multicolumn{3}{|c|}{$\begin{array}{l}\text { Diversidade de profissionais para tarefa } \\
\text { ambiental }\end{array}$} & & $\begin{array}{l}\text { tência de especificaçã } \\
\text { as responsabilidades } \\
\text { terentes ao cargo do } \\
\text { profissional }\end{array}$ & & $\begin{array}{l}\text { Tempo para transição de } \\
\text { cargo }\end{array}$ \\
\hline Unidade & & $\%$ & \multicolumn{3}{|c|}{$\begin{array}{l}\text { Quantidade de formações acadêmicas } \\
\text { distintas }\end{array}$} & & - & & Ano(s) \\
\hline Descrição & & $\begin{array}{l}\text { Verifica o atendimento ao } \\
\text { planos ambientais propostc } \\
\text { para os empreiteiros }\end{array}$ & \multicolumn{3}{|c|}{$\begin{array}{l}\text { Verifica a diversidade de profissionais, } \\
\text { contribuindo para a eficiência da gestão } \\
\text { ambiental e melhorando as perspectivas } \\
\text { sobre o meio ambiente no órgão rodoviário }\end{array}$} & $\begin{array}{r}\text { Instri } \\
\text { aos } \\
\text { respo } \\
\text { deve }\end{array}$ & $\begin{array}{l}\text { umentos de orientaçã } \\
\text { servidores públicos a } \\
\text { respeito das suas } \\
\text { onsabilidades, direitos } \\
\text { eres inerentes ao carg }\end{array}$ & & $\begin{array}{l}\text { Tempo necessário para os } \\
\text { profissionais ascenderem de } \\
\text { cargo dentro do órgão }\end{array}$ \\
\hline \multirow{5}{*}{$\begin{array}{l}\text { Níveis de } \\
\text { desempenho }\end{array}$} & 1 & 100 & \multicolumn{3}{|c|}{5} & & Existe & & 1 \\
\hline & 2 & 75 & \multicolumn{3}{|c|}{4} & & $\begin{array}{l}\text { ste, mas necessita de } \\
\text { elhorias/ atualizações }\end{array}$ & & 2 \\
\hline & 3 & 50 & \multicolumn{3}{|c|}{3} & & $\begin{array}{l}\text { o existe, mas está em } \\
\text { elaboração }\end{array}$ & & 3 \\
\hline & 4 & 25 & \multicolumn{3}{|c|}{2} & & Não existe & & 4 \\
\hline & 5 & 0 & \multicolumn{3}{|c|}{1} & & - & & 5 \\
\hline \multicolumn{2}{|l|}{ Critério } & \multicolumn{2}{|c|}{$\begin{array}{c}\text { C1 - Legislações ambientais } \\
\text { específicas }\end{array}$} & \multicolumn{2}{|c|}{$\begin{array}{c}\text { C2 - Burocracia na legislação } \\
\text { (interna) }\end{array}$} & $\mathrm{C3}-\mathrm{Re}$ & $\begin{array}{l}\text { eintegração da faixa } \\
\text { de domínio }\end{array}$ & & C4 - Estrutura jurídica \\
\hline \multicolumn{2}{|l|}{ Indicador } & \multirow{2}{*}{\multicolumn{2}{|c|}{ Atendimento às legislações ambientais }} & \multicolumn{2}{|c|}{$\begin{array}{l}\text { Tempo de antecipação do processo } \\
\text { de renovação do licenciamento } \\
\text { ambiental }\end{array}$} & $\begin{array}{r}\text { Existên } \\
\text { rein }\end{array}$ & $\begin{array}{l}\text { cia de medidas para } \\
\text { tegrar a faixa de } \\
\text { domínio }\end{array}$ & \multicolumn{2}{|c|}{$\begin{array}{c}\text { Existência de departamento } \\
\text { jurídico por superintendência do } \\
\text { órgão }\end{array}$} \\
\hline \multicolumn{2}{|l|}{ Unidade } & & & \multicolumn{2}{|c|}{ Dias } & & - & \multirow{2}{*}{\multicolumn{2}{|c|}{$\begin{array}{l}\text { - } \\
\text { Departamento voltado para } \\
\text { questões jurídicas de } \\
\text { desocupação da faixa de domínio, } \\
\text { desmatamento, vandalismo, } \\
\text { entre outros. }\end{array}$}} \\
\hline \multicolumn{2}{|l|}{ Descrição } & \multirow{2}{*}{\multicolumn{2}{|c|}{$\begin{array}{c}\text { Atendimento à solicitação das licenças } \\
\text { ambientais necessárias aos serviços de } \\
\text { manutenção rodoviária }\end{array}$}} & \multicolumn{2}{|c|}{$\begin{array}{l}\text { Antecipação para levantamento, } \\
\text { preenchimento dos dados e } \\
\text { estudos necessários para dar } \\
\text { entrada na renovação do } \\
\text { licenciamento ambiental }\end{array}$} & $\begin{array}{l}\text { Medida } \\
\text { no órgã } \\
\text { da }\end{array}$ & $\begin{array}{l}\text { as ou procedimentos } \\
\text { ão para reintegração } \\
\text { faixa de domínio }\end{array}$ & & \\
\hline \multirow{5}{*}{$\begin{array}{c}\text { Níveis de } \\
\text { desempenho }\end{array}$} & 1 & & & & 90 & & Existem & & Existe \\
\hline & 2 & Parcial & & & 60 & $\begin{array}{r}\text { Existe } \\
\mathrm{d}\end{array}$ & $\begin{array}{l}\text { m, mas necessitam } \\
\text { de atualizações }\end{array}$ & & $\begin{array}{l}\text { Existe, mas o quadro de } \\
\text { funcionários é deficitário }\end{array}$ \\
\hline & 3 & Não & & & 30 & Não exi & $\begin{array}{l}\text { istem, mas estão em } \\
\text { elaboração }\end{array}$ & & $\begin{array}{c}\text { Não existe, mas está em } \\
\text { elaboração }\end{array}$ \\
\hline & 4 & - & & & 15 & & Não existe & & - \\
\hline & 5 & - & & & 5 & & - & & - \\
\hline Critério & & $\begin{array}{c}\text { D1 - Controle de uso de } \\
\text { materiais }\end{array}$ & $\begin{aligned} \text { D2 }-\mathrm{I} \\
\text { resíc }\end{aligned}$ & $\begin{array}{l}\text { tinação de } \\
\text { s sólidos }\end{array}$ & $\begin{array}{l}\text { D3-Disposiçãc } \\
\text { resíduos de dem }\end{array}$ & de & $\begin{array}{l}\text { D4 - Disposição } \\
\text { resíduos de fresą̨ }\end{array}$ & & $\begin{array}{l}\text { D5 - Maquinários } \\
\text { obsoletos }\end{array}$ \\
\hline Indicador & & $\begin{array}{l}\text { Razão entre a quantidade } \\
\text { de materiais utilizados } \\
\text { sobre a prevista em } \\
\text { projeto }\end{array}$ & $\begin{array}{r}\text { Porcenta } \\
\text { sólid } \\
\text { cor }\end{array}$ & $\begin{array}{l}\text { sem de resíduos } \\
\text { s destinada } \\
\text { etamente }\end{array}$ & $\begin{array}{l}\text { Porcentagem de re } \\
\text { sólidos de demo } \\
\text { destinada correta }\end{array}$ & $\begin{array}{l}\text { síduos } \\
\text { lição } \\
\text { mente }\end{array}$ & $\begin{array}{r}\text { Porcentagem de res } \\
\text { de fresagem dispo } \\
\text { corretamente }\end{array}$ & $\begin{array}{l}\text { duos } \\
\text { cos }\end{array}$ & $\begin{array}{l}\text { Idade média dos } \\
\text { maquinários }\end{array}$ \\
\hline Unidade & & - & & $\%$ & $\%$ & & $\%$ & & Anos \\
\hline Descrição & & $\begin{array}{l}\text { Monitorar os materiais } \\
\text { utilizados na obra, com } \\
\text { foco para evitar o } \\
\text { desperdício dos mesmos }\end{array}$ & $\begin{array}{r}\text { Destina } \\
\text { resíduos } \mathrm{s} \\
\text { obras nov } \\
\text { útil da roc } \\
\text { readequ }\end{array}$ & $\begin{array}{l}\text { ão correta dos } \\
\text { lidos gerados em } \\
\text { ss durante a vida } \\
\text { ovia (duplicação, } \\
\text { ação, acessos). } \\
\end{array}$ & $\begin{array}{r}\text { Destinação corret } \\
\text { resíduos sólidos g } \\
\text { nas obras de manu } \\
\text { da infraestrutur } \\
\text { existente }\end{array}$ & $\begin{array}{l}\text { a dos } \\
\text { arados } \\
\text { tenção } \\
\text { a já }\end{array}$ & $\begin{array}{l}\text { Destinação correta } \\
\text { resíduos gerados } \\
\text { serviço de fresager } \\
\text { pavimento }\end{array}$ & $\begin{array}{l}\text { dos } \\
\text { no } \\
\text { n do }\end{array}$ & $\begin{array}{c}\text { Idade média dos } \\
\text { maquinários e caminhões } \\
\text { utilizados para a } \\
\text { realização dos serviços de } \\
\text { manutenção } \\
\end{array}$ \\
\hline & 1 & 0,9 & & 100 & 100 & & 100 & & 5 \\
\hline & 2 & 0,95 & & 85 & 85 & & 85 & & 10 \\
\hline Niveis de & 3 & 1 & & 75 & 75 & & 75 & & 15 \\
\hline & 4 & 1,05 & & 50 & 50 & & 50 & & 20 \\
\hline & 5 & 1,1 & & 25 & 25 & & 25 & & 25 \\
\hline Critério & & $\begin{array}{l}\text { D6 - Plano de manejo de } \\
\text { material fresado }\end{array}$ & $\begin{array}{r}\text { D7-Reap } \\
\text { materi }\end{array}$ & $\begin{array}{l}\text { oveitamento de } \\
\text { is (demolição) }\end{array}$ & $\begin{array}{l}\text { D8 - Reciclagen } \\
\text { resíduos de fres }\end{array}$ & & D9 - Resíduos quín & icos & $\begin{array}{l}\text { D10 - Transporte de } \\
\text { resíduos sólidos }\end{array}$ \\
\hline Indicador & & $\begin{array}{l}\text { Existência de plano para } \\
\text { controle do material } \\
\text { fresado }\end{array}$ & $\begin{array}{r}\text { Porcenta } \\
\text { reaproveit } \\
\text { na área } r \\
\text { do }\end{array}$ & $\begin{array}{l}\text { dom do material } \\
\text { do de demolição } \\
\text { doviária, exceto } \\
\text { avimento }\end{array}$ & $\begin{array}{r}\text { Porcentagem de } m \\
\text { reciclado oriund } \\
\text { pavimento }\end{array}$ & $\begin{array}{l}\text { laterial } \\
\text { o do }\end{array}$ & $\begin{array}{c}\text { Existência de } \\
\text { procedimento pa } \\
\text { controle dos resíd } \\
\text { químicos } \\
\end{array}$ & & $\begin{array}{c}\text { Existência de } \\
\text { procedimento para } \\
\text { controle do transporte de } \\
\text { resíduos sólidos }\end{array}$ \\
\hline Unidade & & - & & $\%$ & $\%$ & & - & & - \\
\hline Descrição & & $\begin{array}{l}\text { Plano para controle do } \\
\text { material fresado, } \\
\text { fornecendo a } \\
\text { rastreabilidade de geração } \\
\text { até a destinação }\end{array}$ & $\begin{array}{r}\text { Reapro } \\
\text { resíduo } \\
\text { orig } \\
\text { manuten } \\
\text { resíduos } \\
(\mathrm{f}\end{array}$ & $\begin{array}{l}\text { eitamento de } \\
\text { de demolição } \\
\text { hados pela } \\
\text { ão, excluindo os } \\
\text { tos pavimentos } \\
\text { sagem). }\end{array}$ & $\begin{array}{l}\text { Percentual de ma } \\
\text { reciclado oriund } \\
\text { processo de fres }\end{array}$ & $\begin{array}{l}\text { terial } \\
\text { o do } \\
\text { agem }\end{array}$ & $\begin{array}{l}\text { Procedimento pa } \\
\text { controle e fiscalizaç } \\
\text { resíduos químic } \\
\text { oriundos da manut }\end{array}$ & $\begin{array}{l}\text { Ira } \\
\text { ão de } \\
\text { es } \\
\text { enção }\end{array}$ & $\begin{array}{c}\text { Procedimento para } \\
\text { controle e fiscalização do } \\
\text { transporte de resíduos } \\
\text { sólidos na rodovia por } \\
\text { terceiros e pelo próprio } \\
\text { órgão }\end{array}$ \\
\hline & 1 & Existe & & 100 & 100 & & Existe & & Existe \\
\hline Níveis de & 2 & $\begin{array}{c}\text { Não existe, mas está em } \\
\text { elaboração }\end{array}$ & & 85 & 85 & & $\begin{array}{c}\text { Não existe, mas est } \\
\text { elaboração }\end{array}$ & á em & $\begin{array}{l}\text { Não existe, mas está em } \\
\text { elaboração }\end{array}$ \\
\hline desempenho & 3 & Não existe & & 75 & 75 & & Não existe & & Não existe \\
\hline & 4 & - & & 50 & 50 & & - & & - \\
\hline & 5 & - & & 25 & 25 & & - & & - \\
\hline
\end{tabular}


No geral, os indicadores do subgrupo Equipe objetivam definir a qualidade da equipe técnica, avaliando desde questões de pesquisa, treinamento e até sobre a multidisciplinaridade da equipe. Para o grupo Jurídico (C) os indicadores avaliam aspectos jurídicos, legislações ambientais específicas, burocracia e reintegração da faixa de domínio. Já o grupo Materiais (D) possui indicadores voltados para o monitoramento dos materiais utilizados e gerados durante as obras de ampliação, readequação ou manutenção do trecho analisado (plataforma e faixa de domínio). Na Tabela 4 são apresentados os dados compilados da fase de estruturação do grupo Meio biótico (E), subgrupo Fauna e Vegetação.

Tabela 4 - Critérios de avaliação do grupo Meio biótico (E) e subgrupos Fauna e Vegetação

\begin{tabular}{|c|c|c|c|c|c|c|}
\hline Critério & & E1 - Solos & \multicolumn{2}{|r|}{ E2 - Fauna } & \multicolumn{2}{|c|}{ E3 - Vegetação } \\
\hline \multicolumn{2}{|l|}{ Indicador } & $\begin{array}{l}\text { Porcentagem da área do solo } \\
\text { impactada pela rodovia em } \\
\text { manutenção }\end{array}$ & \multicolumn{2}{|c|}{$\begin{array}{l}\text { Porcentagem em relação à pontuação máxima } \\
\text { obtida pela soma aditiva dos } \\
\text { critérios do Subgrupo Fauna. }\end{array}$} & \multicolumn{2}{|c|}{$\begin{array}{l}\text { Porcentagem em relação a pontuação } \\
\text { máxima obtida pela soma aditiva dos } \\
\text { critérios do subgrupo Vegetação. }\end{array}$} \\
\hline \multicolumn{2}{|l|}{ Unidade } & $\%$ & \multicolumn{2}{|r|}{$\%$} & \multicolumn{2}{|c|}{$\%$} \\
\hline Descrição & & $\begin{array}{l}\text { Área do solo da faixa de domínio } \\
\text { impactada pela rodovia em } \\
\text { manutenção (empréstimos e } \\
\text { bota-fora, degradação de áreas de } \\
\text { canteiro de obras, trilhas e } \\
\text { caminhos de serviço). }\end{array}$ & \multicolumn{2}{|c|}{$\begin{array}{l}\text { Situação da fauna presente no entorno da } \\
\text { rodovia, onde são avaliadas desde a questões } \\
\text { de monitoramento até o } \\
\text { controle de animais mortos. }\end{array}$} & \multicolumn{2}{|c|}{$\begin{array}{l}\text { Situação da vegetação presente no entorno da } \\
\text { rodovia, onde são avaliadas desde } \\
\text { questões de manejo adequado até o } \\
\text { controle de árvores exóticas. }\end{array}$} \\
\hline \multirow{5}{*}{$\begin{array}{l}\text { Níveis de } \\
\text { desempenho }\end{array}$} & 1 & 0 & \multicolumn{2}{|r|}{100} & \multicolumn{2}{|l|}{100} \\
\hline & 2 & 5 & \multicolumn{2}{|r|}{75} & \multicolumn{2}{|l|}{75} \\
\hline & 3 & 10 & \multicolumn{2}{|r|}{50} & \multicolumn{2}{|l|}{50} \\
\hline & 4 & 15 & \multicolumn{2}{|r|}{25} & \multicolumn{2}{|l|}{25} \\
\hline & 5 & 20 & \multicolumn{2}{|r|}{0} & \multicolumn{2}{|l|}{0} \\
\hline Critério & & E21 - Contenção/condução de animai & ção de animais & E22 - Controle de animais morto & \multicolumn{2}{|c|}{$\begin{array}{l}\text { E23 - Monitoramento/preservação de } \\
\text { espécies de animais }\end{array}$} \\
\hline Indicador & & $\begin{array}{r}\text { Existência de programa } \\
\text { condução de animai } \\
\text { doméstic }\end{array}$ & $\begin{array}{l}\text { ara contenção e } \\
\text { silvestres e } \\
\text { s }\end{array}$ & $\begin{array}{l}\text { Existência de plano de } \\
\text { ramento, controle e destin } \\
\text { animais mortos }\end{array}$ & $\begin{array}{r}\text { Existência de } \\
\text { monitoramento } € \\
\text { espécies d }\end{array}$ & $\begin{array}{l}\text { programa de } \\
\text { preservação de } \\
\text { e animais }\end{array}$ \\
\hline Unidade & & - & & - & - & \\
\hline Descrição & & $\begin{array}{r}\text { Medidas ou procedim } \\
\text { relacionados à contenção e } \\
\text { silvestres e don }\end{array}$ & $\begin{array}{l}\text { ntos no órgão } \\
\text { ondução de animais } \\
\text { ésticos }\end{array}$ & $\begin{array}{l}\text { ledidas para monitorament } \\
\text { ntrole e destinação correta } \\
\text { animais mortos }\end{array}$ & $\begin{array}{r}\text { Programa de mc } \\
\text { preservação de espéc } \\
\text { tem por objet } \\
\text { equilíbrio do ecossis } \\
\text { rodo }\end{array}$ & $\begin{array}{l}\text { Ditoramento e } \\
\text { es de animais, o qual } \\
\text { ivo garantir o } \\
\text { tema no entorno da } \\
\text { via }\end{array}$ \\
\hline & 1 & Existem & & Existem & Exist & em \\
\hline Níveis de & 2 & Existem, mas necessit & m de ajustes & tem, mas necessitam de ajı & Existem, mas nece & ssitam de ajustes \\
\hline desempenho & 3 & Não existem, mas estãc & em elaboração & xistem, mas estão em elab & Não existem, mas es & tão em elaboração \\
\hline & 4 & Não exist & & Não existem & Não ex & istem \\
\hline Critério & & E31 - Árvores exóticas & E32 - Destinação de podas & $\begin{array}{c}\text { E33 - Espécies } \\
\text { adequadas }\end{array}$ & $\begin{array}{l}\text { E34 - Integração de vegetação } \\
\text { com obras civis }\end{array}$ & $\begin{array}{l}\text { E35 - Manejo } \\
\text { adequado }\end{array}$ \\
\hline Indicador & & $\begin{array}{l}\text { Existência de programa de } \\
\text { monitoramento e controle } \\
\text { de árvores exóticas }\end{array}$ & $\begin{array}{c}\text { Existência de programa de } \\
\text { monitoramento, controle e } \\
\text { destinação de resíduos de } \\
\text { podas }\end{array}$ & $\begin{array}{l}\text { Existência de programa } \\
\text { de verificação e seleção } \\
\text { de espécies de } \\
\text { vegetação adequadas }\end{array}$ & $\begin{array}{l}\text { Existência de programa de } \\
\text { incentivo à implantação de } \\
\text { vegetação em obras civis }\end{array}$ & $\begin{array}{c}\text { Existência de } \\
\text { programa de manejo } \\
\text { de vegetação em } \\
\text { geral }\end{array}$ \\
\hline Unidade & & - & - & - & - & - \\
\hline Descrição & & $\begin{array}{l}\text { Objetivo de diminuir os } \\
\text { riscos com acidentes, } \\
\text { controlar espécies de } \\
\text { árvores no entorno da via }\end{array}$ & $\begin{array}{l}\text { Este material é considerado } \\
\text { como bem público servível. } \\
\text { Sua destinação correta é a } \\
\text { reutilização, reciclagem, } \\
\text { compostagem, recuperação } \\
\text { e o aproveitamento } \\
\text { energético }\end{array}$ & $\begin{array}{l}\text { Objetivo de utilizar } \\
\text { espécies que exijam } \\
\text { poucas frequências de } \\
\text { poda, crescimento lento } \\
\text { e não atrapalham a } \\
\text { visibilidade dos usuários }\end{array}$ & $\begin{array}{l}\text { Vegetação em obras civis } \\
\text { como sinalização viva }\end{array}$ & $\begin{array}{l}\text { O programa deve } \\
\text { conter a } \\
\text { identificação das } \\
\text { espécies, } \\
\text { localização, } \\
\text { manutenção de } \\
\text { árvores e arbustos, } \\
\text { entre outros }\end{array}$ \\
\hline & 1 & Existe & Existe & Existe & Existe & Existe \\
\hline Níveis de & 2 & $\begin{array}{l}\text { Existe, mas necessita de } \\
\text { ajustes }\end{array}$ & $\begin{array}{l}\text { Existe, mas necessita de } \\
\text { ajustes }\end{array}$ & $\begin{array}{l}\text { Existe, mas necessita de } \\
\text { ajustes }\end{array}$ & $\begin{array}{c}\text { Existe, mas necessita de } \\
\text { ajustes }\end{array}$ & $\begin{array}{c}\text { Existe, mas necessita } \\
\text { de ajustes }\end{array}$ \\
\hline desempenho & 3 & $\begin{array}{c}\text { Não existe, mas está em } \\
\text { elaboração }\end{array}$ & $\begin{array}{c}\text { Não existe, mas está em } \\
\text { elaboração }\end{array}$ & $\begin{array}{c}\text { Não existe, mas está em } \\
\text { elaboração }\end{array}$ & $\begin{array}{c}\text { Não existe, mas está em } \\
\text { elaboração }\end{array}$ & $\begin{array}{c}\text { Não existe, mas está } \\
\text { em elaboração }\end{array}$ \\
\hline & 4 & Não existe & Não existe & Não existe & Não existe & Não existe \\
\hline
\end{tabular}

Os indicadores do grupo Meio biótico avaliam os impactos relacionados à fauna, flora e vegetação durante a fase de operação da rodovia. Enquanto que os indicadores do subgrupo Fauna buscam avaliar a situação da fauna presente no entorno da rodovia, tratando sobre questões de 
monitoramento até o controle de animais mortos. Já os indicadores do subgrupo Vegetação objetivam verificar o estado da vegetação presente no entorno da rodovia, abordando questões de manejo adequado até o controle de árvores exóticas.

Para o grupo Segurança viária (F) e Socioambiental (G) os dados compilados da fase de estruturação são apresentados na Tabela 5.

Tabela 5 - Critérios de avaliação do grupo Segurança viária (F) e Socioambiental (G)

\begin{tabular}{|c|c|c|c|c|c|c|c|}
\hline Critério & & \multicolumn{3}{|c|}{ F1 - Árvores no entorno } & \multicolumn{3}{|c|}{ F2 - Monitoramento de acessos } \\
\hline Indicador & & \multicolumn{3}{|c|}{$\begin{array}{l}\text { Existência de programa de monitoramento e ações corretivas } \\
\text { relacionadas à influência das árvores do entorno na segurança } \\
\text { viária }\end{array}$} & \multicolumn{3}{|c|}{$\begin{array}{l}\text { Existência de programa de monitoramento de acessos } \\
\text { irregulares na rodovia }\end{array}$} \\
\hline Unidade & & \multicolumn{3}{|c|}{-} & \multicolumn{3}{|c|}{. } \\
\hline Descrição & & \multicolumn{3}{|c|}{$\begin{array}{l}\text { Objetivo de manter a visibilidade e a faixa de domínio livre de } \\
\text { obstáculos para a segurança dos usuários }\end{array}$} & \multicolumn{3}{|c|}{$\begin{array}{c}\text { Objetivo de evitar a existência deste tipo de acesso } \\
\text { devido a sua potencialidade de causar acidentes, visto } \\
\text { que o mesmo se encontra fora das normas }\end{array}$} \\
\hline \multirow{4}{*}{$\begin{array}{l}\text { Níveis de } \\
\text { desempenho }\end{array}$} & 1 & \multicolumn{3}{|c|}{ Existe } & \multicolumn{3}{|c|}{ Existe } \\
\hline & 2 & \multicolumn{3}{|c|}{ Existe, mas necessita de atualizações/ajustes } & \multicolumn{3}{|c|}{ Existe, mas necessita de atualizações/ajustes } \\
\hline & 3 & \multicolumn{3}{|c|}{ Não existe, mas está em elaboração } & \multicolumn{3}{|c|}{ Não existe, mas está em elaboração } \\
\hline & 4 & \multicolumn{3}{|c|}{ Não existe } & \multicolumn{3}{|c|}{ Não existe } \\
\hline Critério & & $\begin{array}{l}\text { G1 - Depredação } \\
\text { indireta }\end{array}$ & $\begin{array}{l}\text { G2 - Educação } \\
\text { ambiental }\end{array}$ & $\begin{array}{l}\text { G3 - Prevenção de } \\
\text { incêndios }\end{array}$ & $\begin{array}{l}\text { G4 - Integração } \\
\text { com os lindeiros }\end{array}$ & G5 - Vandalismo & $\begin{array}{l}\text { G6 - Ocupações } \\
\text { irregulares }\end{array}$ \\
\hline Indicador & & $\begin{array}{l}\text { Existência de } \\
\text { campanhas sobre } \\
\text { o efeito da } \\
\text { depredação } \\
\text { rodoviária }\end{array}$ & $\begin{array}{l}\text { Existência de } \\
\text { programas de } \\
\text { educação } \\
\text { ambiental }\end{array}$ & $\begin{array}{c}\text { Existência de } \\
\text { campanhas para } \\
\text { prevenção e } \\
\text { combate a } \\
\text { incêndios } \\
\text { ambientais }\end{array}$ & $\begin{array}{l}\text { Existência de } \\
\text { sistemas de } \\
\text { atendimento aos } \\
\text { lindeiros }\end{array}$ & $\begin{array}{c}\text { Existência de } \\
\text { programas contra } \\
\text { o vandalismo nas } \\
\text { rodovias }\end{array}$ & $\begin{array}{l}\text { Existência de } \\
\text { ocupações irregulares } \\
\text { da faixa de domínio }\end{array}$ \\
\hline Unidade & & - & - & - & - & - & - \\
\hline \multicolumn{2}{|l|}{ Descrição } & $\begin{array}{l}\text { Campanhas sobre } \\
\text { a depredação } \\
\text { rodoviária junto } \\
\text { aos lindeiros, em } \\
\text { relação aos danos } \\
\text { gerais causados } \\
\text { pelo tráfego de } \\
\text { maquinários } \\
\text { agrícolas na faixa } \\
\text { de domínio e } \\
\text { plataforma }\end{array}$ & $\begin{array}{l}\text { Tem o objetivo } \\
\text { de conscientizar } \\
\text { os usuários a } \\
\text { respeito da } \\
\text { conservação do } \\
\text { meio ambiente }\end{array}$ & $\begin{array}{l}\text { Campanhas para } \\
\text { prevenção e } \\
\text { combate a } \\
\text { incêndios } \\
\text { ambientais com } \\
\text { objetivo de } \\
\text { conscientizar os } \\
\text { usuários a respeito } \\
\text { dos riscos e danos } \\
\text { ambientais }\end{array}$ & $\begin{array}{c}\text { Sistemas de } \\
\text { atendimento aos } \\
\text { lindeiros através } \\
\text { de canais de co- } \\
\text { municação e inte- } \\
\text { ração }\end{array}$ & $\begin{array}{c}\text { Relacionado com a } \\
\text { existência de pro- } \\
\text { grama contra o } \\
\text { vandalismo nas ro- } \\
\text { dovias }\end{array}$ & $\begin{array}{l}\text { Relacionado com a } \\
\text { existência de } \\
\text { ocupações irregulares } \\
\text { da faixa de domínio }\end{array}$ \\
\hline \multirow{4}{*}{$\begin{array}{c}\text { Níveis de } \\
\text { desempenho }\end{array}$} & 1 & Existe & Existe & Existe & Existe & Existe & Não existe \\
\hline & 2 & $\begin{array}{l}\text { Existe, mas } \\
\text { necessita de } \\
\text { atualizações/ } \\
\text { ajustes }\end{array}$ & $\begin{array}{c}\text { Existe, mas } \\
\text { necessita de } \\
\text { atualizações/ } \\
\text { ajustes }\end{array}$ & $\begin{array}{c}\text { Existe, mas } \\
\text { necessita de } \\
\text { atualizações/ } \\
\text { ajustes }\end{array}$ & $\begin{array}{l}\text { Existe, mas } \\
\text { necessita de } \\
\text { atualizações/ } \\
\text { ajustes }\end{array}$ & $\begin{array}{c}\text { Existe, mas } \\
\text { necessita de } \\
\text { atualizações/ } \\
\text { ajustes }\end{array}$ & $\begin{array}{l}\text { Existem, mas estão } \\
\text { em processo de } \\
\text { desocupação }\end{array}$ \\
\hline & 3 & $\begin{array}{l}\text { Não existe, mas } \\
\text { está em } \\
\text { elaboração }\end{array}$ & $\begin{array}{l}\text { Não existe, mas } \\
\text { está em } \\
\text { elaboração }\end{array}$ & $\begin{array}{l}\text { Não existe, mas } \\
\text { está em } \\
\text { elaboração }\end{array}$ & $\begin{array}{l}\text { Não existe, mas } \\
\text { está em } \\
\text { elaboração }\end{array}$ & $\begin{array}{l}\text { Não existe, mas } \\
\text { está em } \\
\text { elaboração }\end{array}$ & Existem \\
\hline & 4 & Não existe & Não existe & Não existe & Não existe & Não existe & - \\
\hline
\end{tabular}

Os indicadores do grupo Segurança viária (F) buscam monitorar aspectos relacionados à segurança dos usuários através de indicadores direcionados para o monitoramento de acessos irregulares e árvores no entorno da rodovia. Enquanto que os indicadores do grupo Socioambiental (G) visam a avaliação de fatores que afetem a sociedade e sua relação com o meio ambiente, através de indicadores relacionados com a existência de campanhas e programas direcionados para educação ambiental, atendimento aos usuários e prevenção contra incêndios.

Analisando as Tabelas de 1 a 5 percebe-se que, de uma forma geral, os indicadores propostos são de fácil obtenção e muitas vezes poderão ser verificados por meio de uma simples conferência documental. Para adotar os indicadores desta pesquisa na avaliação ambiental de 
uma obra de manutenção rodoviária, é possível que se encontre um entrave quanto a não existência de procedimento de aferição e de registros de determinados indicadores pela instituição responsável pela gestão ambiental. Portanto, para um resultado eficaz será necessária a adoção dos procedimentos para o controle e registro de atividades.

\subsection{Fase de Avaliação}

Nesta etapa foi realizado o julgamento de atratividade entre cada nível dos indicadores e entre os 59 indicadores. Inicialmente o julgamento da atratividade foi moroso, pois julgar com escalas semânticas pareceu ser mais difícil que julgar com escala numérica. Deste modo, recomenda-se um treinamento anterior para que os decisores se habituem ao processo e compreendam o julgamento de atratividade. Devido ao alto volume de questionamentos e comparações, a obtenção do IDA-MR levou 11 horas distribuídas em 6 dias.

Na Tabela 6 são apresentadas a funções de valor (pontuações) de cada indicador a serem usadas no cálculo do IDA-MR. Para os indicadores com níveis de desempenho (ND) qualitativos não é possível pontuações e níveis de desempenho intermediários, ou seja, a pontuação é direta (tabelada) para cada ND estabelecido. Já para os quantitativos, o programa M-Macbeth disponibiliza a função valor na forma gráfica havendo pontuações intermediárias entre os possíveis níveis de desempenho do indicador. A vantagem de uso das equações de ajuste dos gráficos de função valor é que eliminam qualquer erro que possa ocorrer no levantamento gráfico para os valores anotados em campo, pois o resultado será o valor exato da pontuação do indicador atribuída àquele determinado ND.

Desta forma, neste trabalho são apresentadas as equações lineares em função do ND para obter da pontuação dos indicadores abordados no item 5.1. As faixas de valores dos ND que se aplicam a cada equação estão entre parênteses.

Observa-se que, dependendo do ND observado em campo, há a possibilidade de pontuações de valores negativos, bem como acima de 100. No caso dos valores negativos isto representa que aquela situação está abaixo do requisito mínimo de atendimento daquele critério. Para o caso dos valores superiores a 100, entende-se que o desempenho daquele critério está acima do nível satisfatório.

Dentre os 59 parâmetros expressos na Tabela 6, percebe-se que o indicador A4 (porcentagem do trecho com erosão) possui pontuação máxima igual a 200 pontos e mínima de -260 pontos e, portanto, a maior amplitude de pontuação (460 pontos). Isso significa que uma obra de manutenção que possui $50 \%$ de seu trecho com erosão, levando em consideração a área da plataforma e faixa de domínio, impactará com uma pontuação negativa de -260 pontos no desempenho ambiental. A maior pontuação negativa em comparação aos outros indicadores reflete a preocupação de que neste indicador o ND esperado não seja atingido.

É importante esclarecer que sem estarem definidos os pesos de ponderação dos indicadores e do grupo ao qual ele pertence, não é possível identificar em qual das situações o impacto negativo no índice global será maior. Porém, se observa que os decisores consideraram uma maior atratividade para a erosão (indicador A4).

Percebe-se ainda que em alguns indicadores há repetição da equação da reta, significando que para os decisores os ND ali inclusos possuem diferenças de atratividade iguais. Ainda, nas equações relativas a apenas 8 dos indicadores (A1, A4, A5, B44, D1, D5 e E1) o coeficiente angular é negativo, portanto quanto menor for o ND, maior a pontuação atingida nos indicadores. 
Tabela 6 - Função de valor (pontuação) de cada critério a ser usado no cálculo do IDA-MR

\begin{tabular}{|c|c|c|c|}
\hline \multicolumn{4}{|c|}{ Pontuação (Função de Valor) de cada critério em função do Nível de Desempenho (ND) } \\
\hline$A 1=-4 N D+100(0<N D \leq 10)$ & $A 1=-12 N D+180(10<N D \leq 15)$ & $A 1=-8 N D+120(15<N D \leq 25)$ & $\mathrm{A} 1=-2,4 \mathrm{ND}-20(25<\mathrm{ND} \leq 50)$ \\
\hline $\mathrm{A} 2=150$ (ND = Existe $)$ & $\begin{array}{c}\mathrm{A} 2=100(\mathrm{ND}=\text { Existe, mas necessita de } \\
\text { melhoria })\end{array}$ & $\begin{array}{c}\mathrm{A} 2=0(\mathrm{ND}= \\
=\text { Não existe, mas está em } \\
\text { elaboração) }\end{array}$ & $\mathrm{A} 2=-50$ (ND = Não existe) \\
\hline $\mathrm{A} 3=140(\mathrm{ND}=$ Existe $)$ & $\begin{array}{c}\mathrm{A} 3=100(\mathrm{ND}=\text { Existe, } \text { mas necessita de } \\
\text { melhoria) }\end{array}$ & $\begin{array}{c}\mathrm{A} 3=0 \text { (ND = Não existe, mas está em } \\
\text { elaboração) }\end{array}$ & $A 3=-40$ (ND = Não existe) \\
\hline$A 4=-10 N D+200(0<N D \leq 10)$ & $A 4=-20 N D+300(10<N D \leq 15)$ & $A 4=-13 N D+195(15<N D \leq 25)$ & $A 4=-5,2 N D(25<N D \leq 50)$ \\
\hline$A 5=-15 N D+175(0<N D \leq 5)$ & $A 5=-20 N D+200(5<N D \leq 10)$ & $A 5=-15 N D+150(10<N D \leq 15)$ & $A 5=-25 N D+300(15<N D \leq 20)$ \\
\hline$A 6=2,2 N D-87(100<N D \leq 85)$ & $A 6=3,3 N D-180,5(85<N D \leq 75)$ & $A 6=3,4 N D-188(75<N D \leq 65)$ & $A 6=3,3 N D-181,5(65<N D \leq 55)$ \\
\hline$A 7=50 \mathrm{ND}(4<\mathrm{ND} \leq 3)$ & $A 7=50 \mathrm{ND}(3<\mathrm{ND} \leq 2)$ & $A 7=100 N D-100(2<N D \leq 1)$ & $A 7=175 \mathrm{ND}-175(1<\mathrm{ND} \leq 0)$ \\
\hline$A 8=140(N D=$ Existe $)$ & $\begin{array}{c}\mathrm{A} 8=100(\mathrm{ND}=\text { Existe }, \text { mas necessita de } \\
\text { melhoria })\end{array}$ & $\begin{array}{c}\mathrm{A8}=0 \text { (ND = } \\
\text { Não existe, mas está em } \\
\text { elaboração) }\end{array}$ & A8 $=-40$ (ND = Não existe) \\
\hline$B 1=2,28 N D-128(100<N D \leq 75)$ & $\mathrm{B} 1=1,72 \mathrm{ND}-86(75<\mathrm{ND} \leq 50)$ & $\begin{array}{c}\mathrm{B} 1=2,28 \mathrm{ND}-114(50<\mathrm{ND} \leq 25) \\
\mathrm{B} 2=0(\mathrm{ND}=\text { Existe, mas não está em }\end{array}$ & $\mathrm{B} 1=1,72 \mathrm{ND}-100(25<\mathrm{ND} \leq 0)$ \\
\hline $\begin{array}{c}B 2=100 \text { (ND = Existe, funciona } 24 \mathrm{~h}) \\
B 3=150 \text { (ND = Existe) }\end{array}$ & $\begin{array}{c}\mathrm{B} 2=50(\mathrm{ND}=\text { Existe, funcionamento parcial) } \\
\mathrm{B} 3=100 \text { (ND = Existe, mas necessita de } \\
\text { melhorias })\end{array}$ & $\begin{array}{c}\text { operação/Não existe }) \\
\text { B3 = } 0 \text { (ND = Não existe, mas está em } \\
\text { elaboração) }\end{array}$ & $\mathrm{B} 3=-50$ (ND = Não existe) \\
\hline$B 4=3 N D-125(100<N D \leq 75)$ & $B 4=4 N D-200(75<N D \leq 50)$ & $B 4=4 N D-200(50<N D \leq 25)$ & $B 4=3,04 N D-176(25<N D \leq 0)$ \\
\hline$B 41=2 N D-100(100<N D \leq 75)$ & $\mathrm{B} 41=2 \mathrm{ND}-100(75<\mathrm{ND} \leq 50)$ & $B 41=2,2 N D-110(50<N D \leq 25)$ & $\mathrm{B} 41=2,2 \mathrm{ND}-110(25<\mathrm{ND} \leq 0)$ \\
\hline$B 42=20 N D+20 \quad(5<N D \leq 4)$ & $\mathrm{B} 42=35 \mathrm{ND}-40 \quad(4<\mathrm{ND} \leq 3)$ & $B 42=35 N D-40(3<N D \leq 2)$ & $\mathrm{B} 42=30 \mathrm{ND}-30(2<\mathrm{ND} \leq 1)$ \\
\hline $\mathrm{B} 43=140$ (ND = Existe) & $\begin{array}{c}\mathrm{B} 43=100(\mathrm{ND}=\text { Existe, } \text { mas necessita de } \\
\text { melhorias })\end{array}$ & $\begin{array}{c}\mathrm{B} 43=0 \text { (ND = Não existe, mas está em } \\
\text { elaboração) }\end{array}$ & $\mathrm{B} 43=-40$ (ND = Não existem) \\
\hline$B 44=-100 N D+300(1<N D \leq 2)$ & $B 44=-100 N D+300(2<N D \leq 3)$ & $B 44=-75 N D+200(3<N D \leq 4)$ & $B 44=-100 N D+300(4<N D \leq 5)$ \\
\hline $\mathrm{B} 5=140(\mathrm{ND}=$ Existem $)$ & $\begin{aligned} \text { B5 }=100(\text { ND }= & \text { Existem, mas necessitam de } \\
& \text { atualizações })\end{aligned}$ & $\begin{aligned} \mathrm{B} 5=0(\mathrm{ND}= & \begin{array}{c}\text { Não existe, } \text { mas estão em } \\
\text { elaboração })\end{array}\end{aligned}$ & B5 = -40 (ND = Não existem) \\
\hline $\mathrm{B} 6=\mathrm{B} 8=\mathrm{B} 9=\mathrm{B} 10=140$ (ND = Existe $)$ & $\begin{array}{c}\mathrm{B} 6=\mathrm{B} 8=\mathrm{B} 9=\mathrm{B} 10=100(\mathrm{ND}=\text { Existe}, \text { mas } \\
\text { necessita de atualizações })\end{array}$ & $\begin{array}{c}\mathrm{B} 6=\mathrm{B} 8=\mathrm{B} 9=\mathrm{B} 10=0(\mathrm{ND}=\text { Não existe } \\
\text { mas está em elaboração })\end{array}$ & $\mathrm{B} 6=\mathrm{B} 8=\mathrm{B} 9=\mathrm{B} 10=-40$ (ND = Não existe) \\
\hline $\mathrm{B} 7=140$ (ND = Existe $)$ & $\begin{array}{c}\mathrm{B} 7=100(\mathrm{ND}=\text { Existe, } \text { mas necessita de } \\
\text { atualizações })\end{array}$ & $\begin{array}{c}\text { B7 = } 0 \text { (ND }=\text { Não existe ou Não existe, mas } \\
\text { está em elaboração) }\end{array}$ & 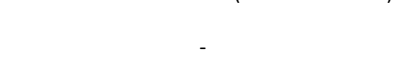 \\
\hline $\mathrm{B} 11=100(\mathrm{ND}=\mathrm{Sim})$ & $\mathrm{B} 11=0(\mathrm{ND}=$ Parcial $)$ & $B 11=-100(N D=N a ̃ o)$ & - \\
\hline$B 12=100(N D=\operatorname{Sim})$ & $\begin{aligned} \mathrm{B} 12= & 0(\mathrm{ND}=\text { Não, mas está em } \\
& \text { desenvolvimento })\end{aligned}$ & B12 = -100 (ND = Não) & - \\
\hline$B 13=10 N D-50(100<N D \leq 75)$ & $B 13=10 N D-50(75<N D \leq 50)$ & $B 13=10 N D-50(50<N D \leq 25)$ & $B 13=10 N D-50(25<N D \leq 0)$ \\
\hline$B 14=10 N D+80(4<N D \leq 2)$ & $\mathrm{B} 14=50 \mathrm{ND}(2<\mathrm{ND} \leq 1)$ & $B 14=50 N D(1<N D \leq 0)$ & - \\
\hline $\mathrm{C} 1=100(\mathrm{ND}=\mathrm{Sim})$ & $\mathrm{C} 1=0$ (ND = Parcial) & $\mathrm{C} 1=-130$ (ND =Não) & - \\
\hline$C 2=1,6667 N D-50(90<N D \leq 60)$ & $C 2=1,6667 N D-50(60<N D \leq 30)$ & $C 2==3,3333 \mathrm{ND}-100(30<\mathrm{ND} \leq 15)$ & $C 2=5 x-125(15<N D \leq 5)$ \\
\hline $\mathrm{C} 3=120(\mathrm{ND}=$ Exitem $)$ & $\begin{array}{c}\text { C3 }=100 \text { (ND = Existem, mas necessitam de } \\
\text { atualizações) } \\
\text { C4 }=0 \text { (Existe, mas o quadro de funcionários }\end{array}$ & $\begin{array}{c}\mathrm{C3}=0 \text { (ND = Não existem, mas estão em } \\
\text { elaboração) }\end{array}$ & $C 3=-20$ (ND = Não existem) \\
\hline $\begin{array}{c}C 4=100(N D=\text { Existe }) \\
D 1=-2000 N D+2000 \\
\quad(0,9<N D \leq 0,95)\end{array}$ & é deficitário) & $C 4=-110$ (Não existe) & 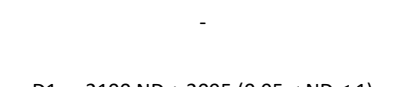 \\
\hline & $D 1=-2000 N D+2000(0,95<N D \leq 1)$ & $D 1=-2200 N D+2200(0,95<N D \leq 1)$ & $D 1=-2100 N D+2095(0,95<N D \leq 1)$ \\
\hline $\begin{aligned} D 2= & D 3=D 4=2 N D-100 \\
& (100<N D \leq 85)\end{aligned}$ & $\begin{aligned} \mathrm{D} 2= & \mathrm{D} 3=\mathrm{D} 4=3 \mathrm{ND}-185 \\
& (85<\mathrm{ND} \leq 75)\end{aligned}$ & $\begin{aligned} \mathrm{D} 2= & \mathrm{D} 3=\mathrm{D} 4=1,6 \mathrm{ND}-80 \\
& (75<\mathrm{ND} \leq 50)\end{aligned}$ & $\begin{array}{c}\mathrm{D} 2=\mathrm{D} 3=\mathrm{D} 4=2,8 \mathrm{ND}-140 \\
(50<\mathrm{ND} \leq 25)\end{array}$ \\
\hline $\mathrm{D} 5=-9 \mathrm{ND}+145(5<\mathrm{ND} \leq 10)$ & $\begin{array}{c}\mathrm{D} 5=-11 \mathrm{ND}+165(10<\mathrm{ND} \leq 15) \\
\mathrm{D} 6=0(\mathrm{ND}=\text { Não existe, mas está em }\end{array}$ & $\mathrm{D} 5=-11 \mathrm{ND}+165(15<\mathrm{ND} \leq 20)$ & $D 5=-9 N D+125(20<N D \leq 25)$ \\
\hline $\mathrm{D} 6=100(\mathrm{ND}=$ existe $)$ & elaboração) & D6 $=-50$ (ND = Não existe) & - \\
\hline$D 7=2 N D-70(100<N D \leq 85)$ & $\mathrm{D} 7=4,5 \mathrm{ND}-282,5(85<\mathrm{ND} \leq 75)$ & $\mathrm{D} 7=2,2 \mathrm{ND}-110(75<\mathrm{ND} \leq 50)$ & $\mathrm{D} 7=1,6 \mathrm{ND}-80(50<\mathrm{ND} \leq 25)$ \\
\hline $\mathrm{D} 8=2 \mathrm{ND}-100(100<\mathrm{ND} \leq 85)$ & $\mathrm{D} 8=3,5 \mathrm{ND}-227,5(85<\mathrm{ND} \leq 75)$ & $\mathrm{D} 8=1,4 \mathrm{ND}-70(75<\mathrm{ND} \leq 50)$ & $\mathrm{D} 8=1,6 \mathrm{ND}-80(50<\mathrm{ND} \leq 25)$ \\
\hline $\mathrm{D} 9=\mathrm{D} 10=100(\mathrm{ND}=$ existe $)$ & $\begin{array}{c}\mathrm{D} 9=\mathrm{D} 10=0(\mathrm{ND}=\text { Não existe, } \text { mas está em } \\
\text { elaboração })\end{array}$ & $\mathrm{D} 9=\mathrm{D} 10=-50$ (ND = Não existe) & 年 \\
\hline$E 1=-13,334 N D+166,67(0<N D \leq 5)$ & $E 1=-20 N D+200(5<N D \leq 10)$ & $\begin{aligned} E 1= & -13,334 N D+133,34 \\
& (10<N D \leq 15)\end{aligned}$ & $\begin{aligned} E 1= & -13,354 N D+133,64 \\
& (15<N D \leq 20)\end{aligned}$ \\
\hline $\begin{array}{c}E 2=1,1428 N D-14,28 \\
(100<N D \leq 75)\end{array}$ & $\begin{aligned} E 2= & 2,8572 N D-142,86 \\
& (75<N D \leq 50)\end{aligned}$ & $E 2=1,7144 N D-85,72(50<N D \leq 25)$ & $E 2=2,2856 \mathrm{ND}-100(25<\mathrm{ND} \leq 0)$ \\
\hline $\mathrm{E} 21=120(\mathrm{ND}=$ existem $)$ & $\begin{array}{c}\mathrm{E} 21=100\left(\mathrm{ND}=\begin{array}{c}\text { Existem }, \text { mas necessitam de } \\
\text { ajustes })\end{array}\right.\end{array}$ & 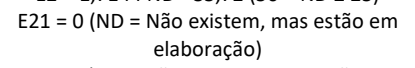 & E21 = -20 (ND = Não existem) \\
\hline $\mathrm{E} 22=120(\mathrm{ND}=$ existem $)$ & $\begin{array}{c}\mathrm{E} 22=100(\mathrm{ND}=\mathrm{Existem}, \text { mas necessitam de } \\
\text { ajustes) }\end{array}$ & $\begin{array}{c}\mathrm{E} 22=0 \text { (ND = Não existem, mas estão em } \\
\text { elaboração) }\end{array}$ & $E 22=-20$ (ND = Não existem) \\
\hline $\mathrm{E} 23=120(\mathrm{ND}=$ existem $)$ & $\begin{aligned} E 23=100(N D= & \begin{array}{c}\text { Existe, } \\
\text { ajustes })\end{array}\end{aligned}$ & $\begin{array}{c}\mathrm{E} 23=0 \text { (ND = Não existe, mas está em } \\
\text { elaboração) }\end{array}$ & $E 23=-20$ (ND = Não existe) \\
\hline$E 3=1,3332 N D-33,32$ & $E 3=2,6668 \mathrm{ND}-133,34$ & & \\
\hline$(100<N D \leq 75)$ & $(75<N D \leq 50)$ & $E 3=2 N D-100(50<N D \leq 25)$ & $E 3=2,6668 N D-116,67(25<N D \leq 0)$ \\
\hline $\mathrm{E} 31=125(\mathrm{ND}=$ existem $)$ & $\begin{array}{c}\text { E31 }=100(\mathrm{ND}=\text { Existe, } \text { mas necessita de } \\
\text { ajustes })\end{array}$ & $\begin{array}{c}\mathrm{E} 31=0 \text { (ND = Não existe, mas está em } \\
\text { elaboração) }\end{array}$ & E31 = -25 (ND = Não existe) \\
\hline $\begin{aligned} \mathrm{E} 32= & \mathrm{E} 33=\mathrm{E} 34=\mathrm{E} 35=120 \\
& (\mathrm{ND}=\text { existem })\end{aligned}$ & $\begin{array}{c}\mathrm{E} 32=\mathrm{E} 33=\mathrm{E} 34=\mathrm{E} 35=100 \\
(\mathrm{ND}=\text { Existe, mas necessita de ajustes })\end{array}$ & $\begin{array}{c}\mathrm{E} 32=\mathrm{E} 33=\mathrm{E} 34=\mathrm{E} 35=0 \text { (ND = Não existe, } \\
\text { mas está em elaboração) }\end{array}$ & $\begin{array}{c}\mathrm{E} 32=\mathrm{E} 33=\begin{array}{c}\mathrm{E} 34=\mathrm{E} 35=-20 \\
\text { existe })\end{array}\end{array}$ \\
\hline $\mathrm{F} 1=150(\mathrm{ND}=$ Existe $)$ & $\begin{array}{c}\mathrm{F} 1=100(\mathrm{ND}=\text { Existe, mas necessita de } \\
\text { atualizações) } \\
\mathrm{F} 2=100(\mathrm{ND}=\text { Existe, mas necessita de }\end{array}$ & $\begin{array}{c}F 1=0\left(N D=\begin{array}{l}\text { Não existe, } \text { mas está em } \\
\text { elaboração })\end{array}\right. \\
F 2=0 \text { (ND = Não existe, mas está em }\end{array}$ & $\mathrm{F} 1=-25$ (ND = Não existe) \\
\hline $\mathrm{F} 2=140(\mathrm{ND}=$ Existe $)$ & atualizações) & elaboração) & $F 2=-40(N D=$ Não existe $)$ \\
\hline $\mathrm{G} 1=150(\mathrm{ND}=$ Existe $)$ & $\begin{array}{c}\mathrm{G} 1=100 \text { (ND }=\text { Existe, mas necessita de } \\
\text { atualizações) }\end{array}$ & $\begin{array}{c}\mathrm{G} 1=0 \text { (ND = Não existe, mas está em } \\
\text { elaboração) }\end{array}$ & G1 = -50 (ND = Não existe) \\
\hline $\mathrm{G} 2=140(\mathrm{ND}=$ Existe $)$ & $\begin{array}{c}\mathrm{G} 2=100(\mathrm{ND}=\text { Existe, mas necessita de } \\
\text { atualizações) }\end{array}$ & $\begin{array}{c}\mathrm{G} 2=0 \text { (ND = Não existem, mas estão em } \\
\text { elaboração) }\end{array}$ & - \\
\hline $\mathrm{G} 3=140$ (ND = Existe) & $\begin{array}{c}\mathrm{G3}=100(\mathrm{ND}=\text { Existem, mas necessitam de } \\
\text { atualizações })\end{array}$ & $\begin{array}{c}\mathrm{G3}=0 \text { (ND= Não existem, mas estão em } \\
\text { elaboração) }\end{array}$ & - \\
\hline $\mathrm{G} 4=140(\mathrm{ND}=$ Existe $)$ & $\begin{array}{c}\mathrm{G} 4=100(\mathrm{ND}=\text { Existem, mas necessitam de } \\
\text { atualizações })\end{array}$ & $\begin{array}{c}\mathrm{G} 4=0 \text { (ND = Não existem, mas estão em } \\
\text { elaboração) }\end{array}$ & - \\
\hline $\mathrm{G} 5=140$ (ND = Existe) & $\begin{array}{c}\mathrm{G} 5=100(\mathrm{ND}=\text { Existem, mas necessitam de } \\
\text { atualizações })\end{array}$ & 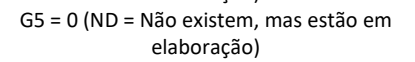 & - \\
\hline $\mathrm{G6}=100$ (ND = Não Existem) & $\begin{aligned} \mathrm{G} 6= & 0(\mathrm{ND}=\text { Existem, mas estão em } \\
& \text { processo de desocupação })\end{aligned}$ & $\mathrm{G} 6=-100(\mathrm{ND}=$ Existem $)$ & - \\
\hline
\end{tabular}


Na Tabela 7 são apresentadas as matrizes de hierarquização dos grupos e de julgamento de atratividade entre os grupos. Destaca-se que, apesar dos grupos (A) e (D) terem obtidos a mesma nota, os decisores julgaram que o impacto ambiental causado pelos materiais (D) ocorre com maior rapidez e agressividade do que com o grupo (A).

Tendo em vista o volume de dados da composição do IDA-MR, buscou-se sintetizar, em forma de arborização, os pesos de cada critério, grupos e subgrupos por meio da Figura 5. Desta maneira, há uma rápida interpretação e leitura da abrangência e contribuição de todos os itens que compõem a matriz de avaliação do IDA-MR.

Tabela 7 - Matrizes de hierarquização e de julgamento de atratividade entre grupos

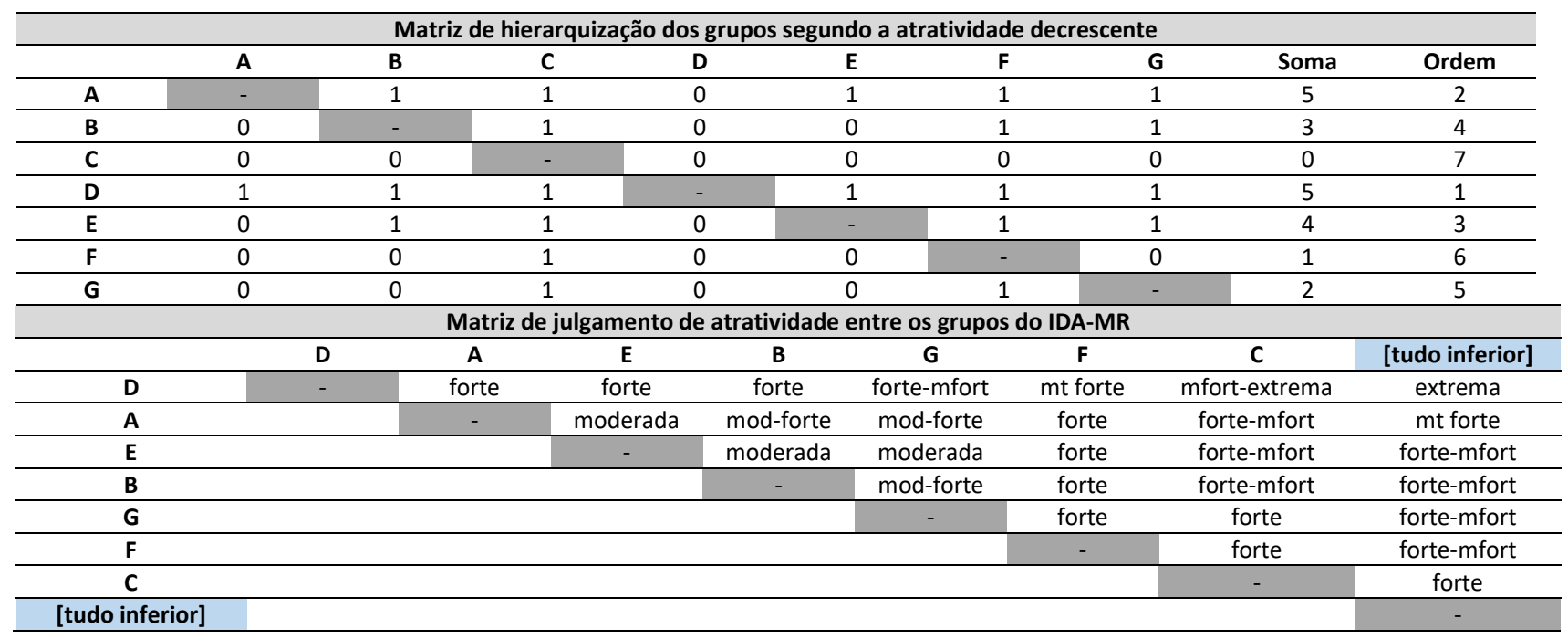

Observa-se na Figura 5 que o indicador A4, que apresentou a maior amplitude na função valor (pontuação), não foi o de maior peso dentro do grupo ao qual ele pertence, bem como nem o seu grupo possui o maior peso no IDA-MR. 0 grupo materiais (D) é o de maior peso e um dos que possui maior número de indicadores. Isso resultará numa compensação, uma vez que, devido o maior número de indicadores em relação a outros grupos, poderia ocorrer uma menor representatividade dele na composição do índice.

Quanto a uma análise geral dos pesos das áreas de interesse (grupos) para a composição do índice, observou-se que o maior impacto para o desempenho ambiental, segundo os julgadores, é o de "Materiais". Isso se deve principalmente pelo fato que o desperdício de materiais, a inadequação do transporte, do destino, da disposição e do reaproveitamento dos resíduos (sólidos e químicos) oriundos das atividades de manutenção, bem como o uso de maquinários obsoletos (dispersão de poluentes, alto consumo de combustível e risco de vida para os trabalhadores), representam danos ambientais graves e imediatos demonstrando que o desempenho ambiental dos serviços não foi satisfatório. Já o grupo "Jurídico" teve o menor peso na formação do índice, pois se referem, na sua maioria, à prevenção dos impactos de forma indireta.

Portanto, com base na Equação 1, o IDA-MR poderá ser obtido através da soma aditiva entre os grupos de acordo com a Equação 2:

$$
\boldsymbol{I D A}-\boldsymbol{M} \boldsymbol{R}=0,19 \cdot A+0,15 . B+0,05 * C+0,23 . D+0,16 \cdot E+0,09 . F+0,13 . G
$$

Na configuração apresentada na Equação 2 o resultado do IDA-MR está compreendido entre -50 e 150 pontos. Para facilitar a apresentação e compreensão final do IDA-MR, optou-se pela normalização do índice, fixando os valores finais entre 0 (valor mínimo) e 100 (valor máximo). 
Assim, o resultado obtido pelo IDA-MR deverá ser enquadrado nos níveis de desempenho propostos, através da equação 3, para caracterizar a situação do desempenho ambiental do trecho analisado. Na Figura 6 é apresentada uma proposta para a escala de classificação do desempenho ambiental dos serviços da manutenção rodoviária.

$$
\text { IDA }-\boldsymbol{M} \boldsymbol{R}_{\text {Final }}=0,5 * x+25
$$

onde: $\quad$ IDA-MRFinal: $\quad$ Escala de classificação IDA-MR (0 a 100 pontos);

$\mathrm{x}$ resultado do IDA-MR (-50 a 150 pontos);

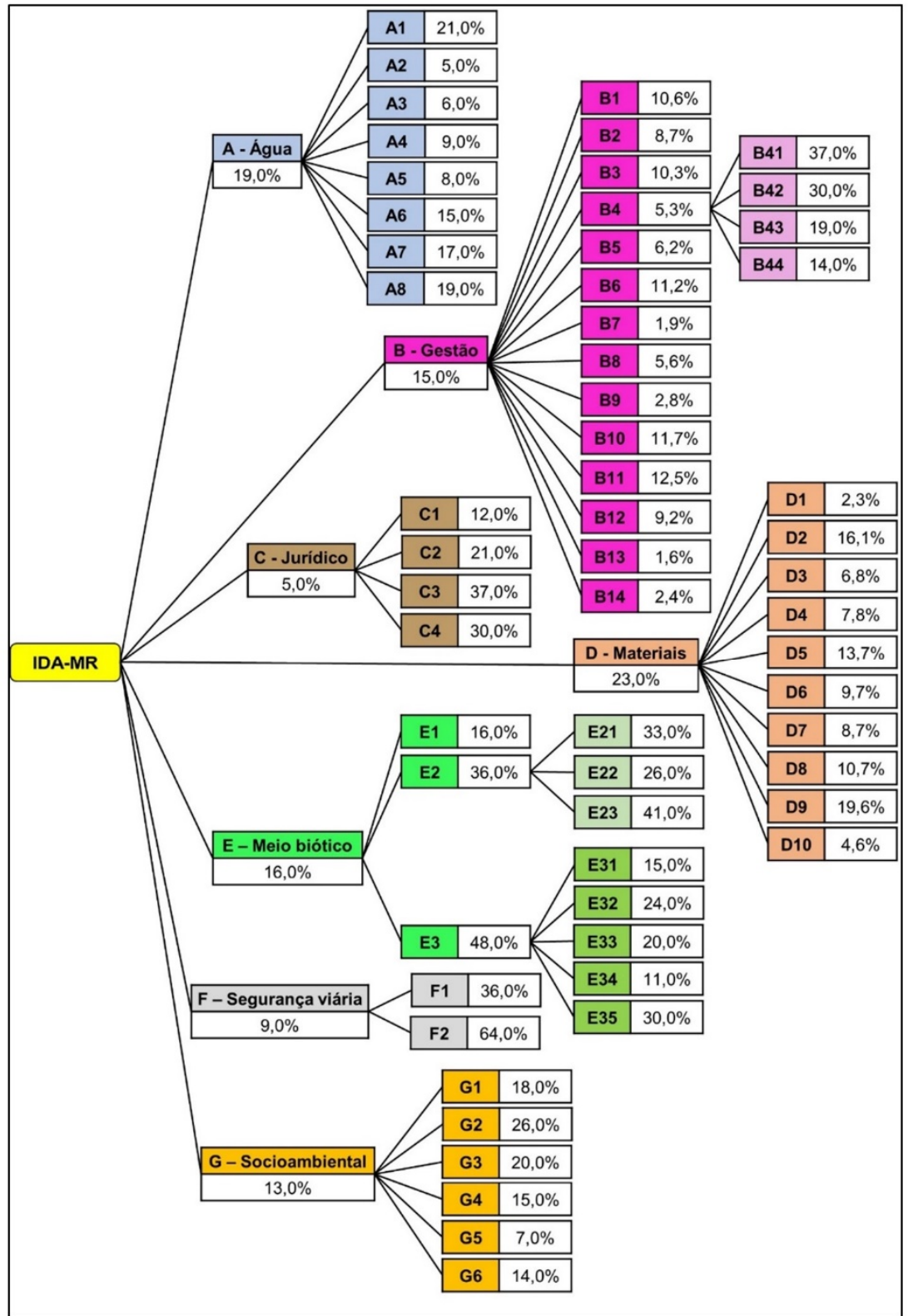

\begin{tabular}{|c|c|}
\hline \multicolumn{2}{|r|}{ LEGENDA } \\
\hline Grupo & Critérios \\
\hline Água (A) & $\begin{array}{l}\text { A1) Água superficial na plataforma; } \\
\text { A2) Assoreamento; A3) Plano de } \\
\text { contingência para desastres com } \\
\text { chuva; A4) Erosão; A5) } \\
\text { Impermeabilidade do solo; A6) } \\
\text { Manutenção dos sistemas de } \\
\text { drenagem; A7) Medidas preventivas; } \\
\text { A8) Programa de monitoramento da } \\
\text { drenagem. }\end{array}$ \\
\hline Gestão (B) & $\begin{array}{l}\text { B1) Compatibilização de projetos } \\
\text { com o meio ambiente; B2) Controle } \\
\text { de carga; B3) Plano de destinação de } \\
\text { resíduos; B4) Equipe técnica; B5) } \\
\text { Controle/ Manutenção da } \\
\text { sinalização; B6) Monitoramento de } \\
\text { defeitos; B7) Patrulha rural; B8) } \\
\text { Plano de contingência ambiental; } \\
\text { B9) Plano de contingência de } \\
\text { acidentes; B10) Plano de } \\
\text { gerenciamento; B11) Programas } \\
\text { ambientais; B12) Suporte financeiro; } \\
\text { B13) Pesquisa; B14) Treinamento. }\end{array}$ \\
\hline $\begin{array}{c}\text { Subgrupo } \\
\text { equipe }\end{array}$ & 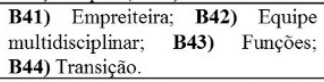 \\
\hline Jurídico (C) & $\begin{array}{l}\text { C1) Legislações ambientais } \\
\text { especificas; C2) Burocracia na } \\
\text { legislação (interna); C3) } \\
\text { Reintegração da faixa de domínio; } \\
\text { C4) Estrutura juridica. }\end{array}$ \\
\hline Materiais (D) & 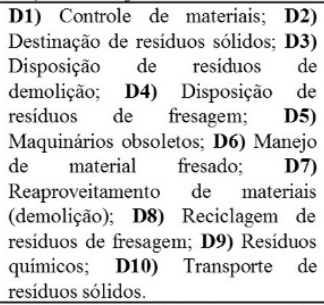 \\
\hline Meio biótico (E) & $\begin{array}{llll}\begin{array}{l}\text { E1) Solos; } \\
\text { Vegetação. }\end{array} & \text { E2) } & \text { Fauna; } & \text { E3) } \\
\end{array}$ \\
\hline $\begin{array}{l}\text { Subgrupo } \\
\text { fauna }\end{array}$ & $\begin{array}{lr}\text { E21) Contenção/condução } & \text { de } \\
\text { animais; E22) Controle de animais } & \text { E23) } \\
\text { mortos; } & \text { de } \\
\text { Monitoramento/preservação } & \text { espécies de animais. }\end{array}$ \\
\hline $\begin{array}{l}\text { Subgrupo } \\
\text { vegetação }\end{array}$ & $\begin{array}{l}\text { E31) Árvores exóticas; E32) } \\
\text { Destinação de podas; E33) Espécies } \\
\text { adequadas; E34) Integração de } \\
\text { vegetação com obras civis; E35) } \\
\text { Manejo adequado. }\end{array}$ \\
\hline $\begin{array}{c}\text { Segurança } \\
\text { viária (F) }\end{array}$ & $\begin{array}{l}\text { F1) Árvores no entorno; } \\
\text { F2) Monitoramento de acessos. }\end{array}$ \\
\hline $\begin{array}{l}\text { Socioambiental } \\
\text { (G) }\end{array}$ & $\begin{array}{l}\text { G1) Depredação; G2) Educação } \\
\text { ambiental; G3) Prevenção de } \\
\text { incêndios; G4) Integração com os } \\
\text { lindeiros; G5) Vandalismo; G6) } \\
\text { Ocupações irregulares. }\end{array}$ \\
\hline
\end{tabular}

Figura 5. Arborização dos pesos dos critérios e grupos na composição do IDA-MR

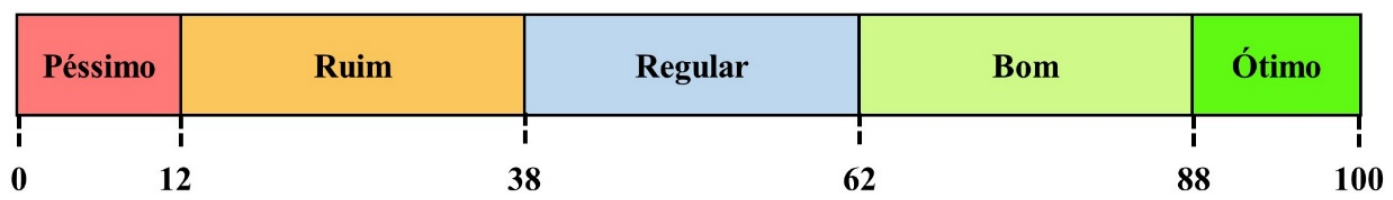

Figura 6. Escala de classificação IDA-MR 
Cabe destacar que alguns itens de avaliação possuem certa regionalidade, ou seja, são problemas e situações que podem ser exclusivos para cada cidade sede das regionais do DER/PR, não ocorrendo em outros lugares do Brasil.

Portanto, durante a aplicação do IDA-MR em outro estado ou até mesmo em outra cidade, pode ser que algum critério não seja necessário para aquela localidade. Nestes casos este indicador deverá ser excluído e os pesos dentro do seu respectivo grupo devem ser redistribuídos entre os critérios restantes.

\section{CONCLUSÕES}

O uso da metodologia MACBETH permitiu parametrizar e operar um índice composto por vários critérios, que abrangem diversas áreas diretamente relacionadas à gestão ambiental em obras de manutenção rodoviária. Além disso, o índice permite aferir o desempenho ambiental de forma interligada e direta, bem como fazer o acompanhamento dinâmico do desempenho ambiental em cada trecho em manutenção.

Durante a análise dos dados originais foi possível observar que a metodologia MCDA-C possibilitou a captação e tradução das opiniões dos entrevistados através da elaboração dos critérios e indicadores. Contudo, quando foram observados os mecanismos sugeridos para a mensuração, verificou-se que algumas medidas não seriam de fácil execução e controle. Diante de tal situação, houve a necessidade do aprimoramento da descrição e sua maneira de mensuração. Assim, e de uma forma geral, ficam pontuadas as principais contribuições desta pesquisa frente ao que foi realizado do trabalho de Jesus (2015).

No início a etapa de julgamento da atratividade foi complexa, pois a utilização da escala semântica dificulta o julgamento dos decisores se comparada com uma escala numérica. Entretanto, percebeu-se a adaptação à forma de avaliação de acordo com a atratividade entre as opções.

Em relação à função de valor dos critérios, estas se apresentam de maneira simples e intuitiva, pois dependendo da avaliação do indicador é necessário apenas a correlação deste na função de valor, seja graficamente (originais do M-MACBETH) ou por meio da equação da reta. Já para os critérios qualitativos a obtenção do resultado é direta, pois existem apenas os níveis estabelecidos, sem a presença de níveis intermediários.

No que se refere ao procedimento experimental no software, a matriz de indicadores do IDAMR foi segmentada por grupo para realizar o julgamento de atratividade, pois o programa só permite reunir um conjunto de critérios por vez. Desta maneira, a operacionalização do IDA-MR se torna manual, pois não é possível agrupar todos os dados em uma única árvore de julgamento para simular os resultados no software. Este problema poderá ser contornado com a automatização do IDA-MR em planilhas eletrônicas.

O IDA-MR pode auxiliar na análise dos impactos ambientais e na padronização das informações necessárias para estimar o desempenho ambiental de obras de manutenção rodoviária. Está demonstrado nesta pesquisa que o índice é uma ferramenta confiável para identificar pontos vulneráveis e passíveis de melhorias. Esta identificação pode resultar em adequações e consequente redução dos impactos ambientais.

\section{AGRADECIMENTOS}

Os autores agradecem à CAPES pelo apoio financeiro e à Universidade Estadual de Londrina (UEL) pela estrutura fornecida à pesquisa. 


\section{REFERÊNCIAS}

Bana e Costa, C. A.; L. Ângulo-Meza e M. D. Oliveira (2013) 0 método MACBETH e aplicação no Brasil. ENGEVISTA, v. 15, n. 1. p. 3-27. DOI: 10.22409 /engevista.v15i1.484.

Bana e Costa, C. A.; P. A. da Silva e F.N. Correia (2004) Multicriteria evaluation of flood control measures: the case of Ribeira do Livramento. Water Resources Management, Netherland, v. 18, p. 263-283. DOI: 10.1023/B:WARM.0000043163.19531.6a.

Bortoluzzi, S. C.; S. R. Ensslin e L. Ensslin (2010) Construção de um modelo de avaliação de desempenho para a gestão financeira de uma empresa de informática. Revista CAP, v. 4, n. 4, p. 12-22. Disponível em: http://revistas.utfpr.edu.br/pb/index.php/CAP/article/view/998. Acesso em: 11 de jan. 2017.

Costa, P. H. da S. e S. R. Granemann (2015) Proposta de metodologia para classificar as empresas de transporte rodoviário interestadual semiurbano de passageiros por nível de serviço. Anais do XXIX Congresso Nacional de Pesquisa e Transportes da ANPET, Ouro Preto, v. 1, p. 1155-1158.

Costa, R. M. e L. E. Sánchez (2010) Avaliação do desempenho ambiental de obras de recuperação de rodovias. Revista Escola de Minas, Ouro Preto, v. 63, n. 2, p. 247-254. Disponível em: www.scielo.br/scielo.php?pid=S0370$44672010000200007 \&$ script=sci_abstract\&tlng=pt. Acesso em: 18 de abril 2017.

Díaz, O. L. C. e L. C. M. Silva (2015) Criterios de sostenibilidad en el subsector vial. Ciencia e Ingeniería Neogranadina, v. 25, n. 2, p. 81-98. DOI: 10.18359/rcin.1433.

Gallardo, A. L. C. F. e L. E. Sánchez (2004) Follow-up of a road building scheme in a fragile environment. Environmental Impact Assessment Review, v. 24, n. 2, p. 47-58. DOI: 10.1016/S0195-9255(03)00136-7.

Gomes, P. R. e T. F. Malheiros (2012) Proposta de análise de indicadores ambientais para apoio na discussão da sustentabilidade. Revista Brasileira de Gestão e Desenvolvimento Regional, v. 8, n. 2, p. 151-169. Disponível em: www.rbgdr.net/revista/index.php/rbgdr/article/view/671. Acesso em: 18 de abril 2017.

Jesus, F. G. de. (2015) Indicadores de desempenho para a gestão ambiental dos serviços de manutenção rodoviária. (Dissertação de Mestrado - Pós-Graduação em Engenharia de Edificações e Saneamento) Universidade Estadual de Londrina - UEL, Londrina, PR, Brasil.

Perdigão, J. G. de L.; E. de V. Fulgêncio; S. A. C. Sousa; J. B. Magalhães Neto e J. S. Dornelas (2012) Processo decisório: um estudo comparativo da tomada de decisão em organizações de segmentos distintos. Anais do IX Simpósio de Excelência em Gestão e Tecnologia, SEGeT, Resende, v. 1, p. 1-17. Disponível em: www.aedb.br/seget/arquivos/artigos12/7416262.pdf. Acesso em: 22 de maio 2017.

Ratton, P.; M. B. Sobanski e E. Ratton (2013) Gestão ambiental de empreendimentos rodoviários estudo de caso - BR-262/MS. Anais do 42a Reunião Anual de Pavimentação, RAPv, $16^{\circ}$ Encontro Nacional de Conservação Rodoviária, Enacor, Gramado, v. 1, p. 1-13. 